\title{
Encapsulation of Calcium Phosphates on Electrospun Nanofibers for Tissue Engineering Applications
}

\author{
Arputharaj Joseph Nathanael ${ }^{1, *(D)}$ and Tae Hwan $\mathrm{Oh}^{2, *}$ \\ 1 Centre for Biomaterials, Cellular and Molecular Theranostics, Vellore Institute of Technology (VIT), \\ Vellore 632014, India \\ 2 School of Chemical Engineering, Yeungnam University, Gyeongsan 38541, Korea \\ * Correspondence: ajosephnc@ynu.ac.kr (A.J.N.); taehwanoh@ynu.ac.kr (T.H.O.)
}

check for updates

Citation: Nathanael, A.J.; Oh, T.H. Encapsulation of Calcium Phosphates on Electrospun Nanofibers for Tissue Engineering Applications. Crystals 2021, 11, 199. https://doi.org/ $10.3390 /$ cryst11020199

Received: 18 December 2020

Accepted: 25 January 2021

Published: 18 February 2021

Publisher's Note: MDPI stays neutral with regard to jurisdictional claims in published maps and institutional affiliations.

Copyright: (c) 2021 by the authors. Licensee MDPI, Basel, Switzerland. This article is an open access article distributed under the terms and conditions of the Creative Commons Attribution (CC BY) license (https:// creativecommons.org/licenses/by/ $4.0 /)$.

\begin{abstract}
In the field of tissue engineering, electrospinning is a versatile technique that provides nanofibers with structure similar to that of the extracellular matrix owing to their flexible functionalization. Considerable developments in electrospinning have been made to produce engineered electrospun nanofibers for different biomedical applications. Various biopolymers possess good biocompatibility and biodegradability and are nontoxic in nature. Modification of these biopolymers can enhance or elicit certain properties. One technique of modification is the incorporation of certain inorganic ions or components that can enhance its specific functional characteristics such as mineralization, osseointegration, and bioactivity. Incidentally, calcium phosphate (CaP) materials have proven to be suitable and versatile for biopolymer incorporation and exploration because of their inherent bioactivity and being key mineral constituents of bone and teeth. The addition of $\mathrm{CaP}$ materials to polymers enhances cell infiltration, differentiation, and biomineralization. We aim to provide a broad overview of $\mathrm{CaP}$ material (particularly hydroxyapatite (HA))-incorporated electrospun nanocomposite fibers and their possible applications in tissue engineering. Some key polymer/HA composites were discussed in detail, and a brief discussion on other polymer/HA composites was also provided. Finally, we discussed the future perspectives of this interesting and emerging composite material fabricated via electrospinning.
\end{abstract}

Keywords: hydroxyapatite; calcium phosphate; electrospinning; biocompatibility; tissue engineering; wound healing

\section{Introduction}

Calcium phosphate $(\mathrm{CaP})$ is the key inorganic constituent of teeth and composes approximately $60 \%$ of human bone. It has been used for a long time in dental and orthopedic applications owing to its inherent biocompatibility [1-3]. CaP compounds encourage osteoblast differentiation, which helps bone cells to grow on implanted materials [4,5]. Its biodegradation rate is also appropriate and can be completely replaced by new bone tissues during the process [2,6]. There are various CaP minerals, and the main examples are $\alpha$-tricalcium phosphate $(\alpha$-TCP), $\beta$-tricalcium phosphate $(\beta$-TCP), hydroxyapatite (HA), biphasic calcium phosphate (BPC), and whitlockite (WH), which enable bone tissue development by assimilating well with adjacent tissues [7-9]. Therefore, these mineral components are normally used in dentistry and orthopedic areas as fillers. Furthermore, because of its superior bioactivity, it is also used as a coating material for metallic or polymeric implant materials $[1,10]$. The bioactive characteristic of $\mathrm{CaP}$ comes from its physical and chemical characteristics. The bioactive features of many crystalline CaP compounds have been studied and reported in the literatures. Figure 1 shows the crystalline structure of some of the CaP compounds mentioned above. Although CaP, as a raw material itself, has been generally used for bone regeneration and repair, $\mathrm{CaP}$ composites with other bioactive materials showed better utilization according to various studies [11]. It includes bioactive 
coating material for implant application, altering the mechanical properties, controlling biodegradability, and encapsulating biomolecules and drugs.

A
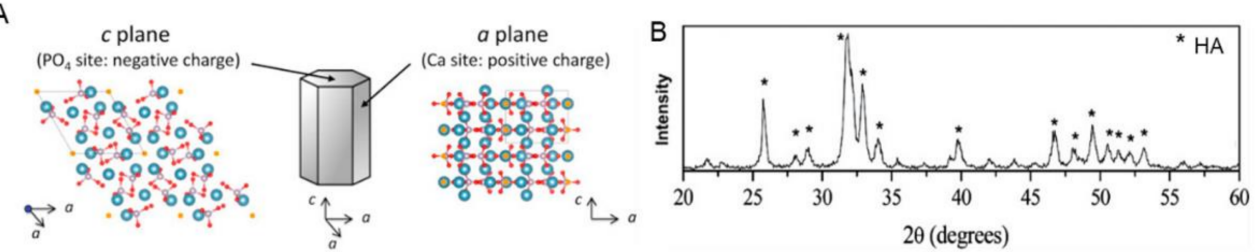

C
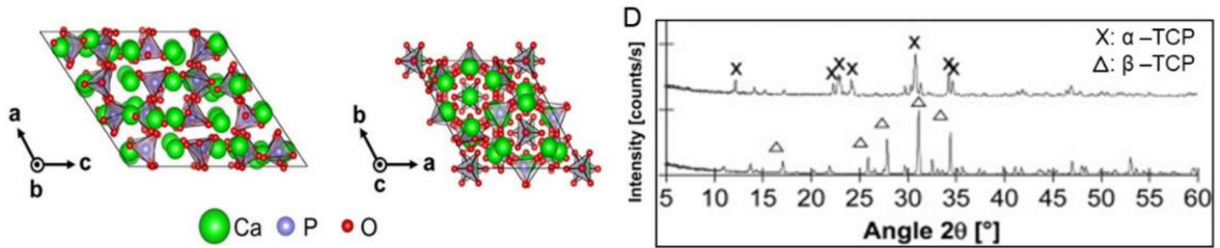

E
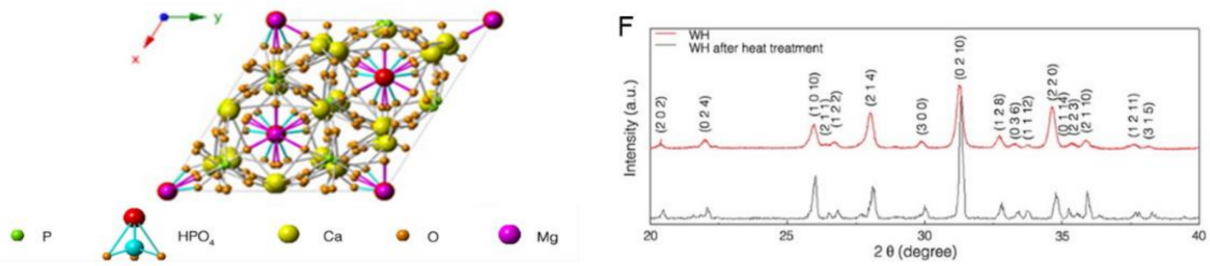

Figure 1. Schematic illustration of the crystal structures of (A) HA, (C) $\alpha$-TCP and $\beta$-TCP, and (E) $\mathrm{WH}$ and the corresponding XRD patterns of (B) HA and (D,F) WH. (Reprinted with permission (A) from the authors of [12], Copyright (2015), Elsevier, (B) from the authors of [13], Copyright (2012), American Chemical Society, (C) from the authors of [14], Copyright (2015), Elsevier, (D) from the authors of [15], Copyright (2008), Elsevier, and (E,F) from the authors of [9], Copyright (2014), American Chemical Society).

Similarly, biocompatible polymers are used in various biomedical applications owing to their inert and hydrophobic nature, and their inability to biodegrade. Depending on their molecular weight, these polymers can be used in various medical applications, wound dressings, implant materials, tissue regeneration, and suture materials [10,16]. Alternatively, biodegradable polymers are preferred and have applications in numerous fields owing to their excellent biocompatibility, nontoxicity, and bioresorbability. As biodegradable polymers degrade and disappear after they serve their functions, they reduce the risk of other surgical procedures [16,17]. For tissue engineering applications, it is vital to know how foreign elements interact with tissues and provide suitable bio-interfaces that can be accepted by host tissue. In this context, new emerging materials called nanohybrids or nanocomposite materials have paved the way for altering the molecular-level interactions of different constituents to produce new and distinctive functional materials with enhanced properties. Recently, the composition of inorganic and polymer hybrid or composite materials has attracted considerable attention as a promising biomaterial, owing to its tunable mechanical properties, biocompatibility, flexibility, low toxicity, and biodegradability. Thus, the combination of $\mathrm{CaP}$ compounds with polymers can be adjusted to emulate the structure and properties of bones. By controlling the percentage of the concerned materials, the desired mechanical properties and bioactivity can be achieved $[6,10,18]$.

Numerous approaches have been developed for producing polymer nanocomposite fibers, mostly based on wet, dry, melt, and gel spinning. Electrospinning is one of the versatile techniques to produce various kinds of polymer as well as nanocomposite polymer fibers. Over the decades, significant progress has been made on the electrospinning process and understanding its mechanism. This advancement leads to an extension of its applications in various fields including biomedical applications. Compared to other available methods, electrospinning has advantages due to its low cost and high productivity. Further, 
electrospinning provides a high level of flexibility and controls over diameter, microstructure, and arrangement of the electrospun nanofibers. Additionally, various materials can be selected for electrospinning and easy incorporation of additives such as nanoparticles. Moreover, various kinds of nanofibers such as core-shell and aligned nanofibers can be prepared by electrospinning. On the other hand, it is difficult to get nanofibers with diameters less than $100 \mathrm{~nm}$ and the yield speed is quiet low in the electrospinning process [19].

In this review, we aim to provide an overview of the latest developments in the design of HA-encapsulated electrospun nanofiber polymer composites and their applications in the field of tissue engineering. Prior to that, a brief overview of fundamental principles of electrospinning, key parameters for electrospinning, and possible applications of these electrospun nanofibers in various fields are provided in the subsequent sections.

\section{Fundamental Principles of Electrospinning}

The first report on the concept of electrospinning was published by Charles V. Boys in 1887 [20]. He discovered that, in the presence of external electric filed, fibers can be drawn from a viscoelastic liquid. This technique opens the door for the development of electrospinning, which is now used for the fabrication of ultrathin fibers in nanometer scale. The history of the development of the electrospinning was recently reported by Xue et al. [21]. The electrospinning setup is quite simple and includes major components such as high-voltage supply, syringe pump, needle (spinneret), and grounded metal collector. Electrospinning is based on electro-hydrodynamic procedure in which a solution droplet is electrified to produce a jet, and then it stretched and elongated to produce fibers. Electrical potential is applied between the tip of a spinneret (polymer droplet) and a grounded collector. Upon electrification of the droplet, it deforms into a Taylor cone due to electrostatic repulsion between the surface charges and a charged jet is expelled from the spinneret. Due to bending instability, after the initial straight line, the jet experiences numerous flogging motions. Finally, the jet is stretched into finer diameter, solidifies, and is deposited on the collector as a solid fiber. The electrospinning process can be categorized into the following steps: (1) charging of the polymer droplet and the creation of a Taylor cone, (2) straight segment of the charged jet, (3) thinning of the charged jet due to electric field, and (4) solidification and deposition of the fiber on a collector. The electrospinning setup and the electrospun jet pathway are shown in Figure 2.

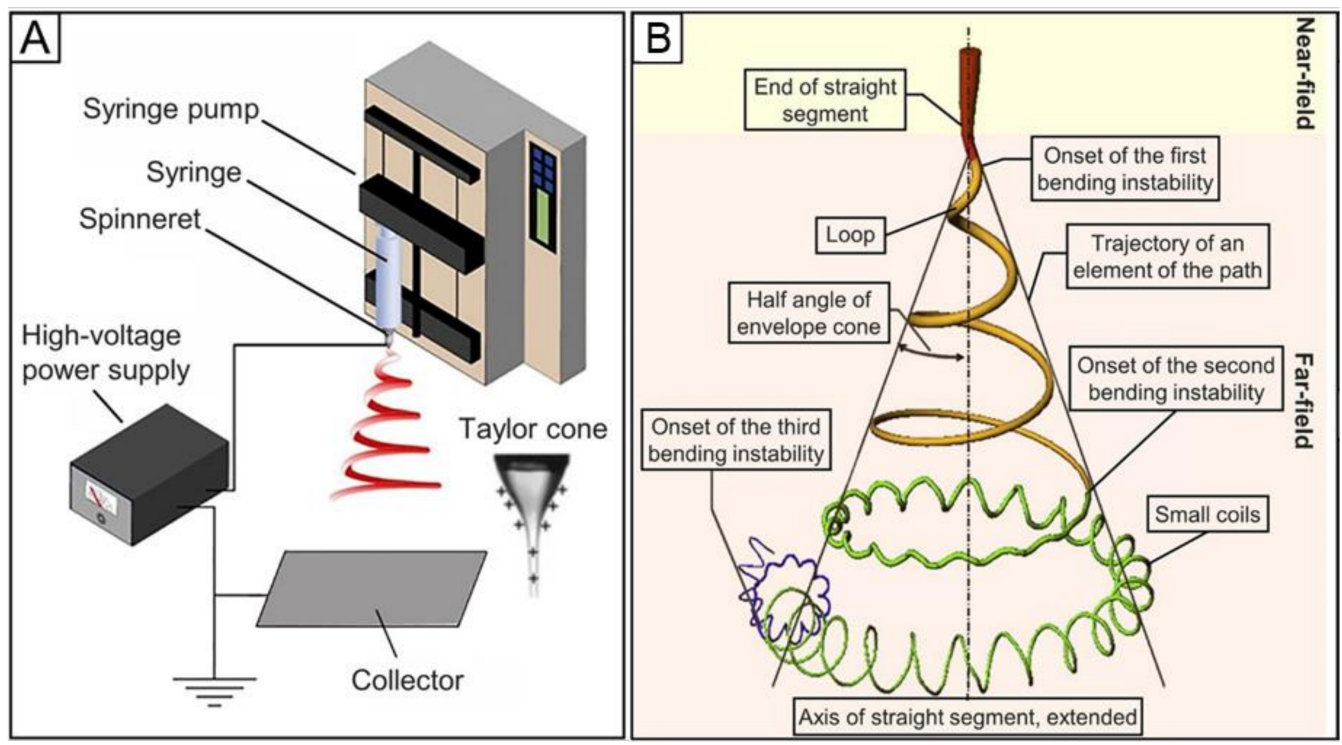

Figure 2. Schematic illustration of (A) the electrospinning setup and (B) the electrospun jet pathway. (Reprinted with permission from the work in [21]. Copyright (2019), American Chemical Society). 
Apart from regular electrospinning, new approaches were also established to regulate the alignment and structure of electrospun nanofibers. These advancements opened its applications in various fields from energy-related application to biomedical applications. Further, this new approaches provide a way for combining different properties emerging from the structure, size, composition, and morphology [19].

\section{Key Parameters for Electrospinning}

There are various parameters that can influence the electrospun nanofibers. These parameters can be classified as follows: (i) solution parameters (which include solvent uses, polymer concentration, surface tension, viscosity, and conductivity), (ii) instrumental parameters (which include applied voltage, flow rate, gauge diameter, tip to collector distance, and collector types), and (iii) environmental parameters (such as humidity and temperature). These parameters mainly determine the properties and the characteristics of the electrospinning nanofibers and therefore it is crucial to understand these parameters and their effects on electrospun nanofibers. Various researchers reported about the effect of electrospinning parameters on the properties of various electrospun nanofibers [22-26].

\subsection{Solution Parameters}

Solution parameters mainly depend on the choice of the solvent and the molecular weight of the chosen polymer. The basic principle behind electrospinning is the uniaxial stretching of the charged jet. Change in the concentration of the polymer solution considerably disturbs the stretching of the charged jet. Different diameter of the fibers can be obtained with the same polymer but with different molecular weight. Therefore, for smooth and continuous nanofibers, polymer with optimal molecular weight should be selected. Spinability of the polymer solution is directly affected by viscosity, surface tension, and conductivity [27]. With lower polymeric concentration (low viscosity), the surface tension and the applied electric field break the polymer chains which results in bead formation. Viscosity is one of the critical parameter for fiber formation. Increasing the concentration increases the viscosity of the solution which ultimately increases the polymer chain entanglement. This helps to produce uniform nanofibers without beads. On the other hand, if the concentration exceeds the optimum value, it will produce defective and beaded fibers. That is, both low and high viscous solutions produce beaded fibers. Surface tension can be controlled by adjusting the applied voltage, which should be high enough to control it. The choice of the solvents also plays a role in controlling the surface tension, since different solvents deploy different surface tensions. In this way, without altering the concentration one can produce smooth fibers by controlling the surface tension to a minimum. Similarly, conductivity also affects the fiber formation. Smooth and thinner fibers can be formed by increasing the conductivity of the polymer solutions. This can be achieved by adding salts like $\mathrm{KCL}, \mathrm{NaCl}$, and $\mathrm{KBr}$ in the polymeric solutions.

\subsection{Instrumental Parameters}

Apart for the characteristics of the polymer solutions, instrumental parameters are also critical in determining the characteristics of the nanofibers. Changing the applied voltage can determine the diameter of the fibers. The formation of a Taylor cone from a spherical droplet and then the formation of fine nanofibers depend on the applied voltage. The applied voltage to produce fine nanofibers varied from polymer to polymer. Increasing the applied voltage resulted in reduced diameter of the fibers due to the stretching of the polymer solution. Further increasing the applied voltage beyond the critical value resulted in bead formation. This is due to the reduction in the size of the Taylor cone but with same flow rate. Flow rate is the applied pressure used to flow the polymer solution through the spinneret. Optimized flow rate (critical value) can produced nanofibers with uniformity and without any beads. This value also varies with different polymers. Increasing the flow rate above the critical value resulted in the formation of beads. Another instrumental parameter is tip to collector distance. This also should be optimized and will be varied 
for different polymers. At a greater distance, fibers will break and produce intermittent fibers. Shorter distance produces beaded and thicker fibers. Tip to collector distance can be optimized to produce uniformly distributed fibers. Further, fiber diameter and the morphology can be influenced by the diameter and shape of the gauge. Finally, in the instrumental parameter, the type of the collector primarily determines the orientation or alignment of the produced fiber. Commonly used collectors are disk, drum, rotating wheels or disks, plate, or pin. Further, collectors can be custom made to satisfy the requirements [28].

\subsection{Environmental Parameters}

Apart from polymer solution and instrumental parameters, environmental parameters such as temperature and humidity also have effect on the characteristics of the nanofiber production $[29,30]$. Depending on the nature of the polymer, the solidification of the charged jet is controlled by the humidity. In some reported study, change in humidity changes the nanofiber diameter [29]. Further, humidity also affects the smooth fiber formation and resulted in beaded fibers or a stop in electrospinning. Additionally, humidity plays a vital role in preparing porous nanofibers [31]. Humidity and temperature are interrelated environmental parameters. Evaporation rate of solvent is increased by temperature which decreases the viscosity of the solution. This leads to decrease in mean fiber diameter.

\section{Possible Applications of Electrospun Nanofibers}

\subsection{Tissue Engineering Applications of Electrospun Nanofibers}

Tissue engineering is a multidisciplinary research field and medical application focused on the reconstruction or regeneration of damaged tissues due to various issues such as disease, aging, and trauma. Recently, research on the extracellular matrix (ECM) and its role in various cell activities such as proliferation and differentiation has attracted much attention. The natural ECM consists of fibrous interwoven structural proteins (primarily collagen) with a 3D network that is tens of hundreds of nanometers in size [32,33]. Electrospinning can produce fibers that mimic the natural ECM with a wide range of materials in a cost-effective manner. Electrospun fibers and composite nanofibers have found extensive applications in various medical fields. On electrospun mats or scaffolds, cell analysis such as differentiation and migration can be analyzed to improve regeneration or repair of tissues by controlling the properties and morphologies of the fibers. For example, 3D scaffolds can be modified to mimic the ECM, which can be used for tissue regeneration by inducing desirable cellular activities. Various parameters such as diameter, functional groups, inorganic components, porosity, and mechanical and biological properties can be optimized for the intended application [21]. Additionally, drugs and biomolecules can be combined into the nanofibers to functionalize and obtain better control of various applications such as drug and gene delivery and proliferation differentiation of cells on nanofiber scaffolds. This application can be extended to cancer diagnoses and treatment. Another area of interest is biomedical device development. Electrospun nanofiber composites can be used as membranes and coatings for devices and implant applications.

Depending on the application area, composite nanofibers can be electrospun in different forms. For wound dressing and healing, a nanofiber scaffold or mat can be used as an ideal material because the large surface area of nanofibers stops fluid buildup by allowing oxygen permeability at the wound site, while efficiently averting bacterial penetration owing to its small pore size [33,34]. Furthermore, it promotes hemostasis, soothes wounds, and absorbs exudates [35]. Similarly, the nanofiber matrix mimics the ECM of the skin in composition and morphology; therefore, electrospun nanofibers can be a promising candidate for skin replacements or repair [35]. The core-shell structure of nanofibers can be used as a delivery vehicle where drugs or biomolecules can be encapsulated in a nonreactive shell and delivered to the target sites [36,37]. Alternatively, for bone tissue engineering, various features should be considered, as bone has a complex architecture, with ECM components ranging from the micro- to nanometer scale. Therefore, the designed materials 
should mimic the ECM, have mechanical properties similar to that of bone, and have a porous structure for cell ingrowth and mass transport [33].

\subsection{Other Applications of Electrospun Nanofibers}

Electrospun nanofibers can be assembled as membranes and can be used in various other potential applications in environmental remediation, biomedical, energy storage, catalysis, sensors, electronics, fuel cells, textile, and optical applications (Figure 3). Various researchers reviewed about the potential applications of the electrospun nanofibers in various fields [27,30,38-41]. Electrospun nanofibers possess high surface area and therefore it is a good candidate for the fabrication of sensor devices. Further, these nanofibers assembly is flexible and incorporation of active ingredients can be achieved easily. Thus, electrospun sensors showed higher sensitivity compared to films of the same material $[39,42]$.

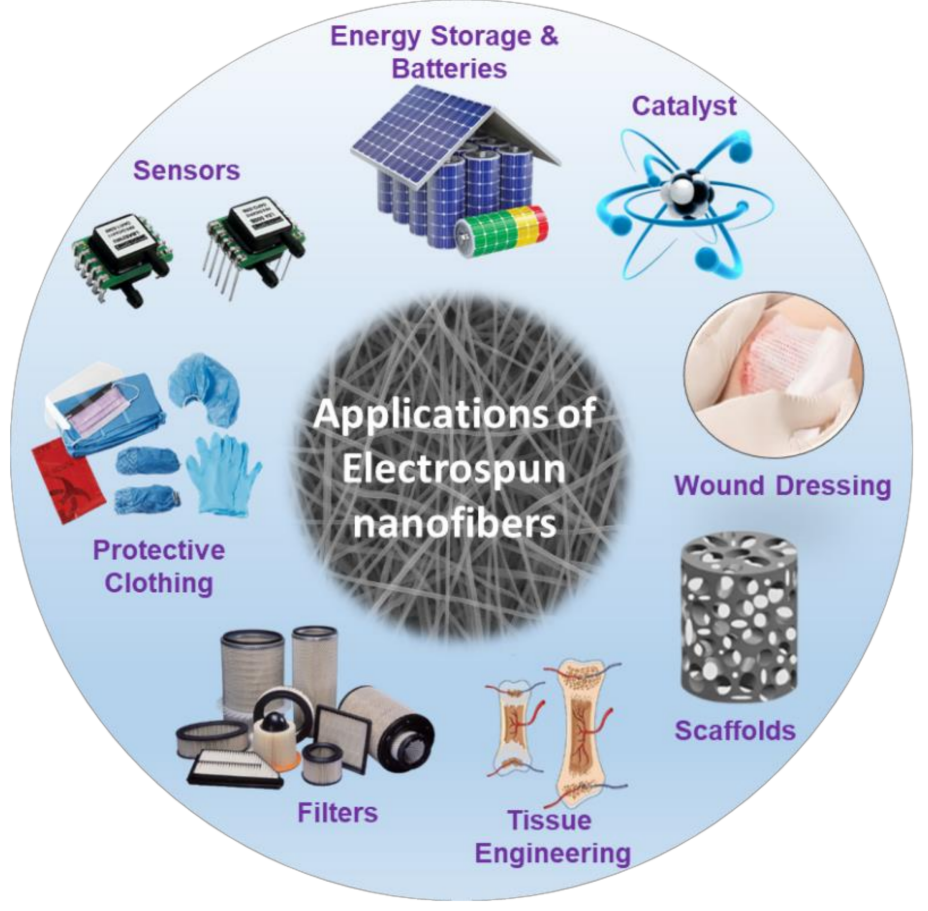

Figure 3. Potential applications of electrospun nanofibers.

Electrospun nanofibers have also been extensively studied for their applications in energy storage and conversion. Due to their higher surface area and controllable porosity, they showed promising results for various energy storage fields. In view of this, electrospun nanofibers are used in lithium-based batteries, fuel cells, solar cells, and supercapacitors $[39,43]$. Sun et al. reviewed the applications of electrospun nanofibers in energy storage and conversion [43]. According to them, in fuel cells, electrospun nanofibers are used as electrolyte membrane and electrode material. Electrospun nanofibers showed better durability and higher electrolyte uptake. Due to their unique fiber morphology, electrospun nanofibers showed higher photoelectric conversion efficiency in dye-sensitized solar cells. Similarly, supercapacitor electrospun nanofibers showed good electrochemical performance and high specific capacity.

Electrospun fibers are used as fibrous catalyst as well. For catalytic methane, reforming $\mathrm{Ni} / \mathrm{Al}_{2} \mathrm{O}_{3}$ fibrous catalyst was used by many researchers [44]. In some cases, the solvent used to prepare the electrospun fibers affects the performance of the catalyst. Cellulose nanofibers were functionalized with different anions and noble metals which showed 100\% selectivity towards the aerobic oxidation of benzyl alcohol and aza-Micheal reaction [45]. Electrospun nanofibers revealed their importance in the filtration of heavy metals and toxins from drinking water and waste waters by adsorption [27,30]. Further, electrospun 
nanofiber are used in drug delivery, immobilization of enzymes, antibacterial wound dressing, desalination, protective coatings, and various other miscellaneous applications.

\section{Encapsulation of Hydroxyapatite (HA) on Electrospun Nanofibers}

Bone is a hard tissue that consists of type I collagen fibrils and apatite mineral nanoparticles. The role that bone plays in our body is vital as it supports and protects various organs. There are two steps involved in the metabolism and regeneration of bone tissues: (i) osteoclasts secrete a particular material that demolishes and absorbs old bone tissues, which produces micropores, and (ii) osteoblasts emit the ECM at the old bone site, fill pores, and accumulate bone minerals [46-48]. These steps produce new regenerated bone tissues. In addition, it is also a storage system for critical mineral components such as calcium and phosphorus. Therefore, a bone tissue engineering scaffold should have mechanical strength comparable to that of the bone, and should supply minerals that can support osteogenesis. Incidentally, biopolymers reinforced with bioactive minerals such as calcium phosphates, silica, and bioactive glass nanoparticles are considered ideal in many ways. Further, it is important to create a 3D microporous system for bone tissue regeneration and repair. Therefore, electrospinning provides a distinctive benefit of fabricating micropores with different diameters of fibers from a micro- to nanoscale. Considering the above, encapsulation of calcium phosphate minerals, such as hydroxyapatite (HA), $\beta$-tricalcium phosphate ( $\beta$-TCP), and biphasic calcium phosphate (BPC), into bioactive polymers may provide a vast area to explore, as several parameters and different materials can be used and tested. The following sections provide the latest account of research and developments in the field of HA-encapsulated electrospun nanocomposite fibers for various tissue engineering applications.

\subsection{Polycaprolactone/Hydroxyapatite (PCL/HA) Nanocomposited Electrospun Fibers}

Polycaprolactone (PCL) is biocompatible and flexible biopolymer. Its biocompatibility was tested in vitro using several types of cells such as fibroblasts [49,50], stem cells [51,52], and a few others [53,54]. Its flexibility is known for its ease of handling to produce different forms such as fibers, films, and microporous materials. [16-19]. Some in vivo tests have also been conducted for various applications and have been found effective $[52,53,55,56]$. Therefore, several researchers have tried to use PCL for tissue engineering applications and attempted to incorporate $\mathrm{HA}$ to induce mineralization and bone formation. Li et al. studied the effect of a higher content of HA (up to $60 \%$ ) on PCL/HA electrospun nanocomposite fibers in an attempt to promote cell infiltration and bone regeneration [57]. They used a single-step electrospinning method and trifluoroethanol as a solvent to prepare the electrospinning solution. The PCL/HA composite showed crystalline phases of Hain XRD analysis. Cell differentiation, regulated cytoskeleton, and cell infiltration were improved by incorporating a high concentration of HA in PCL. They suggested that this scaffold could be a favorable substitute for bone regeneration. The biomineralization ability of PCL/HA or PCL/bioactive glass particles (BGP) electrospun fibers and the crystalline apatite formation was studied and compared by Deliormanlı et al. [58]. Ten weight percent of either HA or BGP was added to PCL to prepare the electrospinning solution. The prepared nanofibers were analyzed for in vitro biomineralization by immersing in simulated body fluid (SBF). Fourier transform infra-red (FTIR) spectroscopic analysis revealed the peaks associated with crystalline $\mathrm{PCl}$ as well as crystalline $\mathrm{HA}$ formation. Further analysis showed that all the fiber composites showed hydrophobic character. Both HA and BGP showed enhanced bioactivity of the fiber. However, the mineralization ability of the HA-added composite was higher than that of the BGP incorporated sample. This fibrous composite can be used in bone tissue engineering, wound dressing, and healing applications. Various other researchers also found that HA incorporation enhanced the functionality of electrospun PCL fibers for tissue engineering applications [49,50,59-62].

In conventional electrospinning methods, it is extremely difficult to produce composite fibrous scaffolds with 3D structures, or with controlled pore size and distribution owing to 
its technical limitations. To overcome complications associated with making 3D electrospun fibrous scaffolds, several researchers have adopted innovative approaches in preparation methods or altered the electrospinning setup to produce 3D scaffolds with hierarchical pore structures. Medical-grade polycaprolactone (m-PCL) was combined with nanocrystalline HA (m-PCL/HA) to produce a composite 3D fibrous structure by melt electrospinning, a direct additive manufacturing method, to enhance cell infiltration, bioactivity, and cell growth [7]. Thermal analysis revealed that the crystalline nature of m-PCL reduced after the addition of HA into the composite scaffold. This m-PCL/HA composite fibrous structure has increased porosity of approximately $96-98 \%$, with an interconnected porous architecture. The results showed that this composite scaffold provides a promising platform for cell growth and infiltration by degrading fast enough in an alkaline environment compared to the pristine m-PCL. Furthermore, HA nanoparticles induced homogeneously distributed cell growth due to a positive cell/material interaction. Therefore, this composite nanofiber may have great potential for mineralized tissue reconstruction and regeneration in tissue engineering applications (Figure 4).
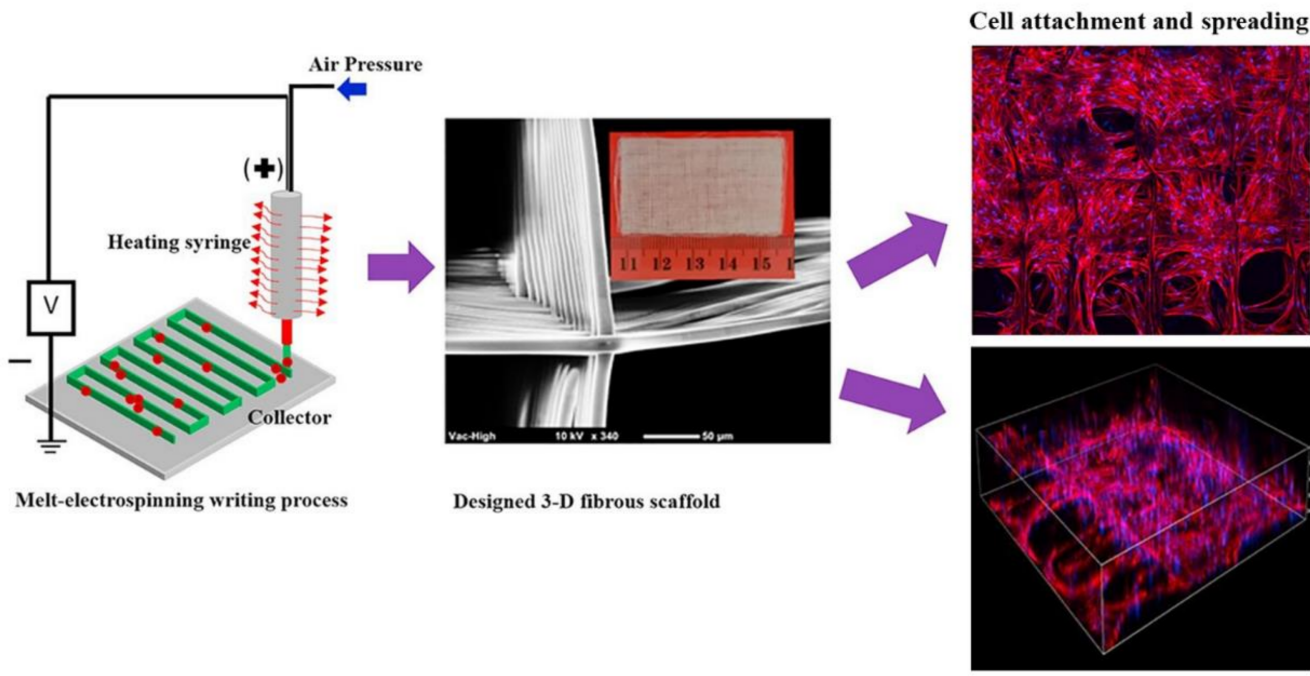

Cell infiltration

Figure 4. Schematic illustration of the melt electrospinning writing process and the scaffold designed by that process, with cell spreading and infiltration. (Reprinted with permission from the work in [7]. Copyright (2018), Elsevier).

Stainless steel meshes were used as a collector instead of the regular collector, in an attempt to produce 3D porous nanofibrous scaffolds by the conventional electrospinning method by Song et al. [48]. Three-dimensional structures were assembled by layer-by-layer addition of prepared fibers using $18 \%$ polycaprolactone/dichloromethane (PCL/DCM) solution as a binder. In this nanofiber, HA was embedded in the fibers and attached to their surface, which had a significant effect on the functionality of composite fibers. Furthermore, it showed interconnected pores of various sizes in the macro- to micrometer range, which supported the cell growth process through the scaffold structure via in vitro studies. Additionally, these composites promoted osteogenesis gene expression by treating the scaffold with alendronate. These studies revealed that this composite nanofiber can be used for bone repair and regeneration. Keivani et al. grafted PCL chains onto HA nanoparticles by ring-opening polymerization of $\varepsilon$-caprolactone (PCL-g-HAp) to reduce inhomogeneous dispersion and increase surface area exposure of $\mathrm{HA}$, thereby increasing its bioactivity [63]. Modified PCL grafted HA (PCL/PCL-g-HAp) composite material was subsequently electrospun and compared with pristine PCL and PCL/HA electrospun materials. Biomineralization showed that all samples were covered with relatively thicker layer of apatite. Cell proliferation and adhesion on PCL/PCL-g-HAp showed enhanced activity, and cells were distributed more uniformly. 
To combine nanofiber and microfiber structures to produce 3D porous structures, Rajzer used both electrospinning and needle punching, as this structure is difficult to produce with electrospinning only [28]. Initially, a mechanical punching process was used to produce a microfibrous nonwoven material, which was subsequently electrospun to produce a hybrid PCL/HA scaffold. PCL/HA composite micro- and nanofibrous materials were obtained by the addition of 5 and $20 \mathrm{wt} \%$ of HA to PCL, respectively. Biomineralization and bioactivity analysis in SBF for $7 \mathrm{~d}$ showed spherical $\mathrm{CaP}$ precipitation, which indicated that this material can be used to separate soft tissue from hard tissue, allowing new bone growth. In another study, AZ31/HA composite material was coated with PCL/HA electrospun fibers for degradable implant applications [64]. Initially, the AZ31 alloy substrate was coated with HA using friction stir processing. Thereafter, the HA-coated AZ31 alloy substrate was pretreated with $1 \mathrm{M} \mathrm{HNO}_{3}$ to produce a crack-free $\mathrm{Mg}(\mathrm{OH})_{2}$ layer. PCL/HA composite electrospun fibers were subsequently coated onto alloy samples. The PCL/HA electrospun coating possessed ECM morphology, and good biomineralization was noted on that surface. Further, it helped to improve cell proliferation and adhesion on the surface. Finally, its degradation was controlled and cane was used as a temporary implant material.

Bone consists of inorganic and organic compounds; thus, using a composite approach to obtain the benefits of inorganic ions in organic compounds is beneficial in bone tissue engineering. Osteoinductive abilities of bone grafting materials determine their success in this field. Bone requires essential ions to maintain its healthy functionality, and its addition to grafting materials has favorable effects [61]. Various ions such as zinc, strontium, silver, gold, and titanium were combined with HA to improve its biocompatibility, osteoconductivity, and resistance against osteomyelitis and microbial attacks. Therefore, biocompatibility, osteoregeneration, and antimicrobial activity of the PCL/HA composite nanofiber improved and imparted added functionality by incorporating certain active ingredients such as inorganic ions, as mentioned above, and biomolecules [59]. Shitole et al. added $\mathrm{ZnO}$ onto PCL/HA electrospun nanocomposite fibers to confer antimicrobial activity along with its existing bioactivity [65]. FTIR and XRD analysis revealed the crystalline behavior of the PCL. The addition of HA did not affect the crystalline structure of PCL. Functional properties can be altered by changing the concentration of $\mathrm{ZnO}$ in the composite fiber. Various concentrations were used, and it was found that $<10 \mathrm{wt} \%$ of $\mathrm{ZnO}$ produced ideal cell proliferation, biomineralization, mechanical stability, and antimicrobial activity. This study showed that $\mathrm{ZnO}$ can be a promising material for bone tissue engineering. Fluorine-incorporated hydroxyapatite (FHA) was added to PCL to form a PCL/FHA nanofiber scaffold tissue engineering application [66]. The PCL/FHA fiber with $10 \mathrm{wt} \%$ FHA showed increased mechanical strength (tensile strength and elastic modulus), biodegradability, and bioactivity. Another interesting nanohybrid polycaprolactone/chitosan (PCL/CS) fibrous membrane was prepared by incorporating Sr-doped calcium phosphate (Sr-CaP/ PCL/CS) for guided bone regeneration [60]. Compared to $\mathrm{PCL} / \mathrm{CS}$ and $\mathrm{CaP} / \mathrm{PCL} / \mathrm{CS}$, (Sr-CaP/ PCL/CS) showed enhanced functionality in various cases such as ion release, biocompatibility, rat bone mesenchymal stem cell (BMSC) adhesion and proliferation, higher alkaline phosphatase (ALP) activity, osteogenic differentiation, and better biomineralization efficiency. Furthermore, the authors found that $\mathrm{Sr}^{2+}$ and CaP ions enhanced angiogenic differentiation of BMSCs. Therefore, Sr-CaP/ PCL/CS is a promising candidate for guided bone regeneration. Rivero et al. showed that incorporation of the 14-3-3 $\varepsilon$ protein in PCL-HA enhanced the osteogenicity of the electrospun scaffold [67]. ALP activity in the PCL-nHA/protein scaffold was four and five times higher than those of the PCL/nHA and pristine PCL scaffolds, respectively. Thus, this combination is extremely promising for bone tissue regeneration.

\subsection{Polylactic or Poly(L-lactic-co-glycolic) Acid/Hydroxyapatite (PLA or PLGA/HA) Nanocomposited Electrospun Fibers}

In the family of polyesters, owing to their interesting mechanical and processing attributes, poly(lactic acid) (PLA) and poly(lactic-co-glycolic acid) (PLGA) are among the most used polymers for drug and gene delivery systems and the most used synthetic 
polymers for a safe and effective vaccine system. They are also approved by the Food and Drug Administration and the European Medicines Agency and are well-documented polymers for clinical and human research. Compared to other biodegradable polyesters, PLA and PLGA are more ecofriendly, as they are produced from sugars using lactic and glycolic acid fermentation [68-70]. These polymers have a wide spectrum of biomedical applications, ranging from tissue regeneration to drug delivery. Their properties can be adjusted and their shapes and sizes are easily managed. Therefore, in the biomedical field, their properties such as degradation rate can be adjusted by controlling the ratio of lactic acid and glycolic acid, to match that of the host tissue without altering other properties such as mechanical strength [69]. As explained earlier, to use PLA or PLGA for tissue regeneration and repair, it is best to make them similar to the ECM. Therefore, the ideal combination for producing ECM-like structures is the addition of CaP to PLA or PLGA and prepared nanocomposite porous scaffolds by electrospinning. The following section will review the latest developments in HA/PLA or HA/PLGA nanocomposite fibers developed via electrospinning for tissue engineering applications.

In the past decade, various reports have been published on HA-incorporated PLA or PLGA nanofibrous composite scaffolds fabricated through electrospinning for tissue engineering applications. Zhou et al. reviewed PLA/CaP and PLGA/CaP composite materials for possible orthopedic applications [71]. Aligned PLGA nanofibrous scaffolds with HA were prepared for application in bone tissue engineering by Jose et al. [72]. When up to $20 \mathrm{wt} \%$ of HA was used, nanoparticle agglomeration was higher than $10 \mathrm{wt} \%$, and fiber breakage occurred at $20 \mathrm{wt} \%$. At $5 \mathrm{wt} \% \mathrm{HA}$, the storage modulus increased from $441 \mathrm{MPa}$ to $724 \mathrm{MPa}$; however, a further increase in HA concentration decreased the storage modulus of the nanofibrous composite. Degradation studies showed a hydrophilic nature and weight loss due to the addition of HA. Thus, the study showed that this material can be used for bone tissue engineering and can be adjusted based on the concentration of HA in the composite fiber.

The latest research on these composites is focused on modifying these materials or including additional components to these composites to enhance their characteristics and study their ability to mimic the ECM for in vivo applications. Multiwalled carbon nanotubes (MWCNTs) and HA-loaded PLGA electrospun nanocomposites for bone tissue engineering applications were studied by Zhang et al. [73]. TEM analysis revealed that the HA particles were very similar to the size and shape of apatite crystals in living bone. The scaffold prepared by these nonwoven fibers mimics ECM morphology, and BMSCs were seeded to analyze the performance of this scaffold. The biocompatibility on this scaffold was good, and cell attachment and proliferation of BMSCs on PLGA/MWCNTs/HA increased compared to those on the PLGA control. Similar work to mimic the natural ECM and improve the biocompatibility, osteoinductivity, and comparable mechanical properties of the PLGA fiber was reported by Fu et al. [74]. In this study, the authors incorporated HA and graphene oxide (GO) with PLGA (PLGA/GO/HA) and studied their improvement over the PLGA control. The addition HA crystals increase the roughness of PLGA/HA fibers. Protein adsorption and hydrophilicity of PLGA/GO/HA were significantly enhanced. The mechanical properties of the nanofibrous matrices improved with the addition of GO nanosheets. GO and HA showed additive effects on promoting cell proliferation and osteogenic differentiation in in vitro studies. Most importantly, they found that the shortcomings of PLGA/HA nanocomposites were overcome by GO addition. Therefore, this combination of the nanofibrous matrix can be a promising candidate for bone tissue regeneration. However, further in vivo analysis is needed before it can be used for clinical applications.

PLGA electrospun fibers were coated with $\mathrm{HA} /$ collagen $(\mathrm{Col})$ to produce a similar ECM morphology, and BMSCs were cultured on nanocomposite fibers [70]. XRD analysis revealed that loading of collagen did not affect the crystalline structure of HA. Interactions between BMSCs and composite nanofibers increased in the presence of HA and HA/Col, which resulted in accelerated cell spreading, increased ALP activity, and increased os- 
teogenic gene expression (Figure 5). Thus, this composite fiber scaffold is a promising material for bone tissue engineering.

8h
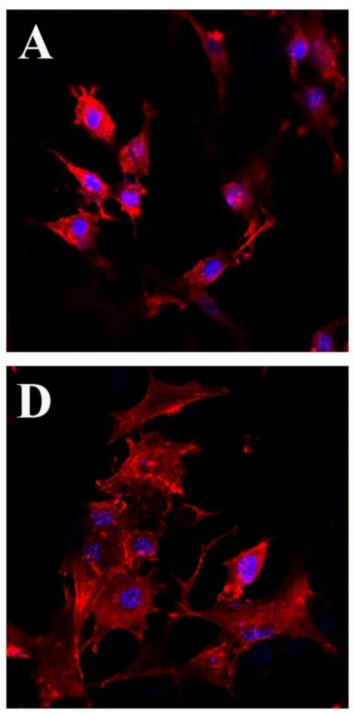
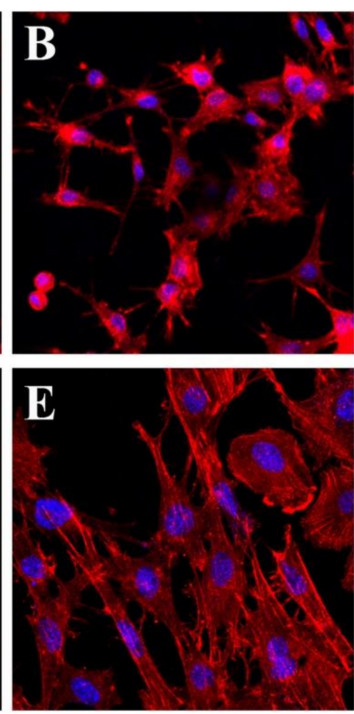
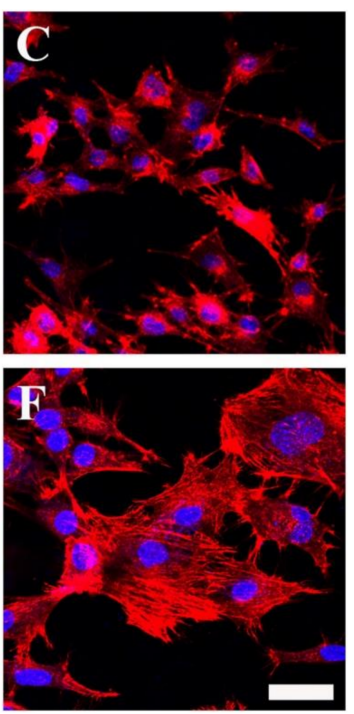

Figure 5. Confocal laser scanning microscope images of cultured bone mesenchymal stem cell (BMSCs) after 8 and $24 \mathrm{~h}$ on (A,D) poly(lactic-co-glycolic acid) (PLGA), (B,E) PLGA/hydroxyapatite (HA), and (C,F) PLGA/HA/collagen (Col) fibers. (Red: F-actin and cell nucleus; blue: $4^{\prime}$,6-diamidino2-phenylindole (DAPI); scale bar = $10 \mu \mathrm{m}$ ). (Reprinted with permission from [70] Copyright (2018), John Wiley and Sons).

In another recent study, various ion $\left(\mathrm{Sr}, \mathrm{Mg}, \mathrm{SiO}_{2}\right.$, and $\left.\mathrm{CO}_{3}\right)$-doped $\mathrm{HA}$ was incorporated into the polymer matrix of polyurethane (PU) and PLA to develop an osteogenic electrospun membrane [75]. Uniformly distributed pores were observed on PU-PLASr-HA membranes. Various doping in HA decreases its crystallinity and distortion in crystal lattice which resulted in peak broadening. The addition of doped HA increased the tensile strength of the membrane, and Young's modulus increased for PU-PLA-MgHA and PU-PLA-Si-HA membranes. Similarly, higher cell proliferation was observed on PU-PLA-C-HA and PU-PLA-Sr-HA membranes. Other samples also displayed good biocompatibility. Furthermore, they showed increased calcium deposition via the Alizarin Red assay. Therefore, by changing the doping material on HA, the properties of the membrane can be adjusted or controlled, thus an excellent candidate for bone and dental regeneration. Another group reported the embedding of different metallic nanoparticles $\left(\mathrm{TiO}_{2}, \mathrm{Au}\right.$, and $\mathrm{Pt}$ ) on a chitosan/PLA/HA nanostructured scaffold [76]. The authors attempted to prepare a scaffold without properties for guided bone regeneration. Initially, PLA was electrospun and chitosan was cross-linked using a microwave-assisted process, followed by HA incorporation and embedding of different metallic nanoparticles (Figure 6). Prepared HA was crystalline in nature as per the XRD analysis. This 3D bioactive hierarchical scaffold consisted of electrospun PLA, cross-linked chitosan, and conductive nanoparticles. It had higher porosity, excellent biomineralization ability, and swelling properties. Scaffolds with $\mathrm{HA}$ and $\mathrm{TiO}_{2}$ showed good cell proliferation, while $\mathrm{HA}$ and $\mathrm{Au}$ nanoparticles showed increased biomineralization ability. Therefore, this type of modification will be a promising tool for bone tissue engineering development. 


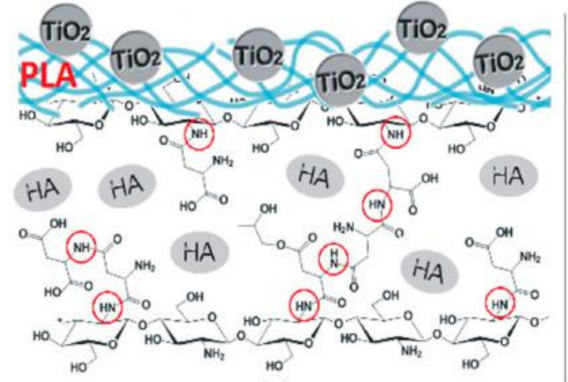

(a)

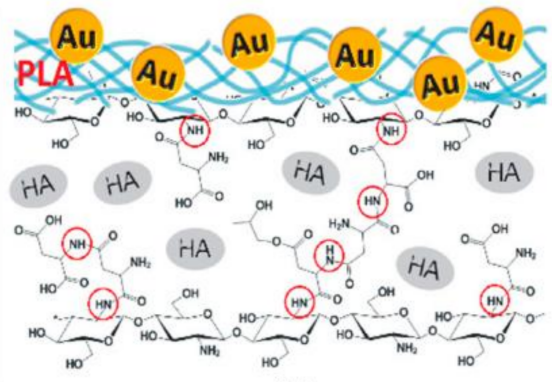

(b)

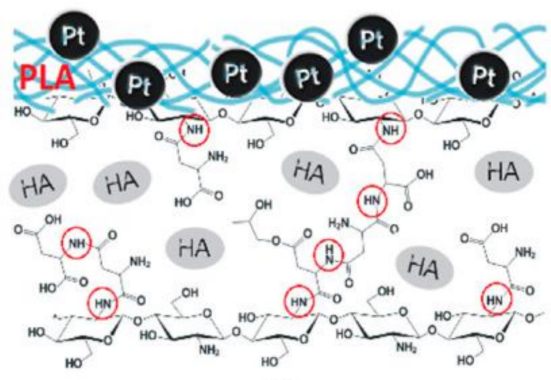

(c)

Figure 6. Schematic representation of a hybrid scaffold embedded with (a) $\mathrm{TiO}_{2}$, (b) $\mathrm{Au}$, and (c) Pt nanoparticles. (Reprinted under Creative Common CC BY license from the authors of [76] Copyright (2020), MDPI).

PLA-based electrospun nanofibers were modified using gelatin (GEL) and carbon nanotubes (CNT) for potential tissue engineering applications [77]. This hybrid material composed of PLA and GEL nanofibers (PLA/GEL) and CNT-modified PLA/GEL nanofibers (PLA+CNT/GEL) was developed by the concurrent electrospinning method. The structures of PLA and GEL nanofibers were retained even after hybrid formation and showed good osteoconductivity without cytotoxicity. Furthermore, these nanofibers showed reduced hydrophobicity, improved mechanical properties, and increased porosity. Kareem et al. showed the optimized condition for micron-sized HA-reinforced electrospun PLA scaffolds and how polymer concentration, filler type, and concentration and morphology affected the mechanical, biomineralization ability, and degradation rate of the scaffold [78]. An alternate PLGA and collagen electrospun multilayer scaffold was proposed for bone tissue engineering by Kwak et al. [79]. This scaffold was prepared with and without HA; HA addition improved the osteogenic properties of the scaffold. This may be due to the asymmetrical charge distribution of HA crystalline planes. The combination of PLGA/Col/HA scaffold showed higher bioactivity than PLGA scaffolds and could be a good candidate for bone tissue engineering.

Apart from tissue engineering applications, drugs and ions can also be incorporated and released using electrospun PLA nanofibers. Amorphous CaP particles have been incorporated into PLA to produce ACP-PLA nanocomposite fibers for drug delivery applications [80]. Water-soluble drugs containing ACP-PLA nanofibers were prepared by introducing a biomolecule lecithin as a biocompatible surfactant to overcome the difficulties of incorporating water-soluble drugs into hydrophobic polymer solutions. The resulting nanocomposite fiber showed simultaneous fast mineralization and sustained drug release in SBF. Further, increased cytocompatibility was observed for prepared nanocomposite fibers, and osteoblast-like cells spread with filopodia. As this material showed positive biocompatibility effects, sustained release, and biomineralization, it can be used for sustainable drug release in tissue engineering.

\subsection{Polyhydroxyalkanoates/Hydroxyapatite (PHA/HA) Nanocomposited Electrospun Fibers}

Polyhydroxyalkanoates (PHAs) are microbial polymers, representing a group of wellknown aliphatic polyesters. Under conditions of stress, e.g., limited available nutrients, microbes generate and store carbon (C) as granules-their energy reservoir [81,82]. Their well-established properties, such as biodegradability, non-toxicity, and biocompatibility, have applications in tissue engineering. Owing to their versatile process and mechanical stability, together with the ability to produce them on a large scale with sustainable methods, this PHA is an exceptional entrant for advanced research compared to other natural polymers. Owing to their biological origin and versatile properties, PHAs have been considered suitable for various clinical and biomedical applications such as drug carriers, anticancer agents, and biodegradable tissue engineering implants [83,84]. In recent years, particular attention has been focused on the simplest form of PHA, poly(3-hydroxybutyric acid), or simply polyhydroxybutyrate (PHB) [85]. The combination of HA and PHA has 
been used for tissue engineering applications for quite a long time. For hard tissues such as bone, the primary focus is on PHB and poly(3-hydroxybutyrate-co-3-hydroxyvalerate) (PHBV) [85]. Various in vitro studies have shown that the combination of HA and PHB induces growth and differentiation of osteoblast cells, encourages ALP activity, and promotes biomineralization [84,86-88]. Electrospinning of PHA for biomedical applications was recently reviewed by Sanhueza et al. [81,89]. This section describes the research developments of electrospun HA/PHA nanofiber composites for tissue engineering applications. Unlike PCL and PLA, only a few reports were available for PHA/HA electrospun nanofiber composites.

Defect-free and smallest possible diameters of HA/PHB nanofibers with sustainable amounts of HA were prepared by electrospinning for bone regeneration applications [85]. Prepared HA nanoparticles possessed hexagonal crystal structure and the crystalline degree of HA was $54 \%$. Various parameters have been optimized to obtain ultrafine nanofibers with HA encapsulation (Figure 7). HA encapsulation on the fibers enhanced cell viability and the spreading of osteoblast cells; the metabolic activity of cells increased with time. This type of hybrid nanofiber can provide a new type of material for bone tissue regeneration.

a

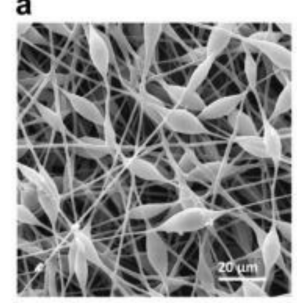

d

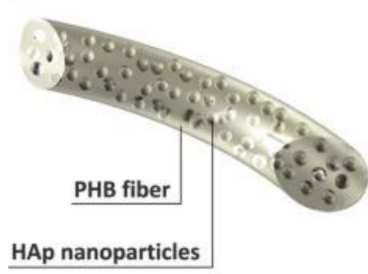

b

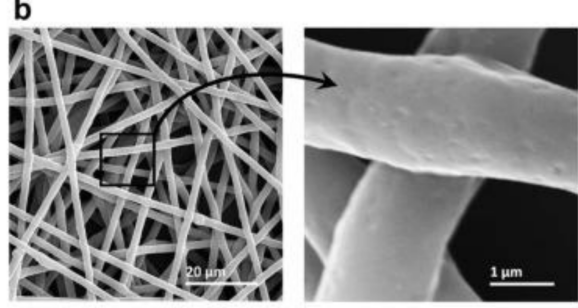

e

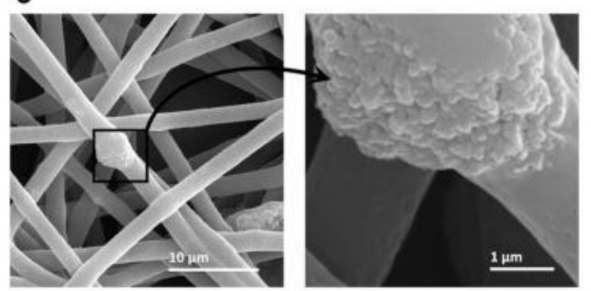

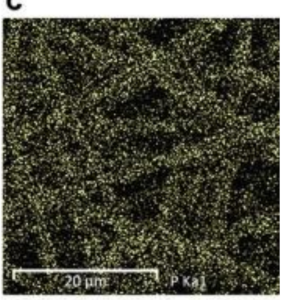

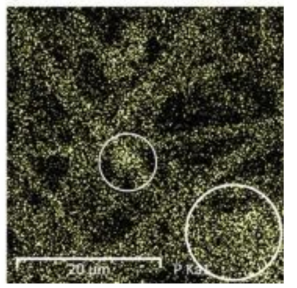

Figure 7. Scanning electron microscopy (SEM) images of electrospun polyhydroxyalkanoates/hydroxyapatite (PHB/HA) fibers (a) with a large number of beads (b) optimized defect-free fibers. (c) Energy-dispersive X-ray spectroscopy (EDX)mapping of $(\mathbf{b}, \mathbf{d})$ schematic illustration of a single PHB/HA nanofiber. (e) SEM micrographs of optimum fibers with aggregated HA particles and (f) the corresponding EDX mapping of subfigure (e). (Reprinted with permission from [85]. Copyright (2016), Elsevier).

Different methods for preparing PHB/HA membranes using electrospinning were proposed by Viezzer et al. [90]. Two methods were adapted to prepare the nanocomposited membrane: direct electrospinning by mixing a PHB solution with HA to produce an electrospinning solution and electrospun composite membrane (C1). In another method, the usual mixing PHB and HA to prepare the composite electrospinning solution was eliminated, owing to its drawbacks such as clogging of the capillary, low dispersion of nanoparticles, and non-homogeneous membrane. Instead, the PHB membrane was prepared by electrospinning, and the electrospun membranes were subsequently impregnated in HA solutions (C2). The surface area and mesoporous structure of both composites C1 and C2 were higher than those of pristine PHB fibers. The C2 membrane was covered with nanostructured HA crystals and produced more mineralization. All samples exhibited increased biocompatibility and cell adhesion and proliferation of MSCs. The presence of HA in the composite induces osteogenic activity, which is positive for this material to be used in bone regeneration applications. The effect of $\beta$-TCP on the PHB/CS electrospun scaffold for application in cartilage tissue engineering was performed by Keikhaei et al. [91]. The addition of $\beta$-TCP increased porosity, mechanical strength, hydrophilicity, and nanofiber 
diameter. Increasing $\beta$-TCP concentration also increased the degradation rate considerably. For bioactivity analysis, a concentration of $7.5 \mathrm{wt} \% \beta-\mathrm{TCP}$ on the PHB/CS electrospun composite showed biomineralization ability in SBF and increased attachment of chondrocytes. Therefore, a $7.5 \mathrm{wt} \% \beta$-TCP on a PHB/CS nanofiber composite would be a good choice for cartilage tissue engineering.

TCP and clay nanoparticle-embedded PHA electrospun nanocomposite fibers were prepared, and their morphological and mechanical properties were analyzed [92]. Compared to clay nanoparticle-embedded PHA fibers, TCP embedded fibers were small and had a nanometer diameter. The mechanical properties of these samples revealed that clayincorporated PHA can be used as a rigid scaffold, whereas the TP-incorporated material can be used as a flexible scaffold for biomedical applications because of its increased elongation at the break point. However, the bioactivity and cytotoxicity of these materials need to be analyzed. Zhao et al. prepared composition-graded PHB/FHA nanocomposite fibers by electrospinning for tissue engineering applications [93]. The advantage of this method is the feasibility of fabricating the material with the desired properties. Compositiongraded films were prepared by changing the concentration of FHA to 0, 1:15, 1:10, 1:8, 1:7, 1:6, and 1:5, and each solution was electrospun individually for $30 \mathrm{~min}$. Thermal and mechanical properties were obtained by controlling the composition of FHA/PHB. Mechanical properties were enhanced by the addition of FHA. Further, cell analysis revealed that this composite fiber possessed good biocompatibility and could be used for tissue engineering applications.

\subsection{Chitosan/Hydroxyapatite (CS/HA) Nanocomposited Electrospun Fibers}

Chitin, the base material for chitosan, is the most copious natural polysaccharide next to cellulose. It is obtained by partial deacetylation of chitin [94,95]. It is a biodegradable natural polymer with inherent characteristics such as biocompatibility, nontoxicity, hemocompatibility, and biodegradability. Therefore, it is a promising material in the medical field and an excellent candidate for drug delivery applications [96]. Although pristine CS can have some excellent characteristics for medical applications, some intended and desired properties can be achieved by modification through chemical or physical methods such as composite or complex formations, fibers, or coatings. Chitosan and its derivatives can be extremely good candidates for tissue engineering scaffolds as they can degrade as tissues are formed without any toxic degradation products $[94,97,98]$. In bone tissue engineering, chitosan can promote cell growth and biomineralization [99]. Compared to other biopolymers such as cellulose, gelatin, and hyaluronic acid, electrospun chitosan showed promising results for tissue regeneration applications. Recently, Qasim et al. reviewed chitosan-based materials fabricated via electrospinning for tissue engineering applications [100]. Few reports are available for the electrospinning of HA/CS nanocomposite fibers for tissue engineering applications. This section reviews some reports on HA/CS electrospun fibers available in literature.

Biocompatible nanocomposites of PU/CS/ $\beta$-TCP electrospun nanofibers have been prepared for tissue engineering and drug delivery applications [101]. Amoxicillin (AMX) was used as a model drug for drug loading and release analysis. Increasing the concentration of $\beta$-TCP decreases the porosity and pore size but marginally increases fiber width. $\mathrm{PU} / \mathrm{CS} / \beta$-TCP acts as a host for anchorage-dependent cells like L929 fibroblasts. For bone tissue engineering applications, 10,3 , and $3 \mathrm{wt} \%$ of PU, CS, and $\beta-\mathrm{TCP}$, respectively, were preferable. The loading and encapsulation efficiencies of the nanocomposite fiber were $61.95 \%$ and $64 \%$, respectively. Similarly, the combination of PCL/CS/Sr-CaP was reported for guided bone regeneration [60], as discussed in Section 3.1. The effect of HA dispersion on cross-linking, mechanical, and bioactive properties has been studied by Liverani et al. [102]. Contrary to the above-mentioned study, the authors found that the fiber diameter decreased with the addition of HA. The mechanical and bioactive (biomineralization) properties of the sample increased with the addition of HA. Biomimetic HA/CS nanofibrous composites were studied for their efficiency in bone tissue engineering ap- 
plications [103]. Initially, the HA/CS composite solution was prepared by the chemical co-precipitation method. HA showed crystalline structure and CS showed semicrystalline structure. Even after forming HA/CS composite, the crystalline nature was still retained. Thereafter, a small amount (10 wt \%) of ultrahigh molecular weight poly(ethylene oxide) (UHMWPEO) was added as a fiber-forming stabilizer. HA/CS nanofibers were successfully formed with a diameter of $214 \mathrm{~nm}$. In vitro cell analysis and human osteoblast cells revealed that $\mathrm{HA}$ incorporation led to substantial bone formation compared to the pristine CS scaffold. In another study, silver ion-doped $\mathrm{CaP}$ was added to $\mathrm{CS}$ to form electrospun nanocomposite fibers for guided bone regeneration with antibacterial activity [104]. Addition of Ag had little effect on crystal structure of HA. Ag-CaP/CS fibers were prepared via one-step electrospinning and subsequently cross-linked with vanillin. Incorporation of $\mathrm{CaP}$ provides ECM morphology, and the mineralization ability of the composite fiber increased (Figure 8). Moreover, Ag ions were released and inhibited bacterial growth and adhesion. Furthermore, this material was cytocompatible with bone marrow cells. Therefore, this composite material can be used for guided bone regeneration.
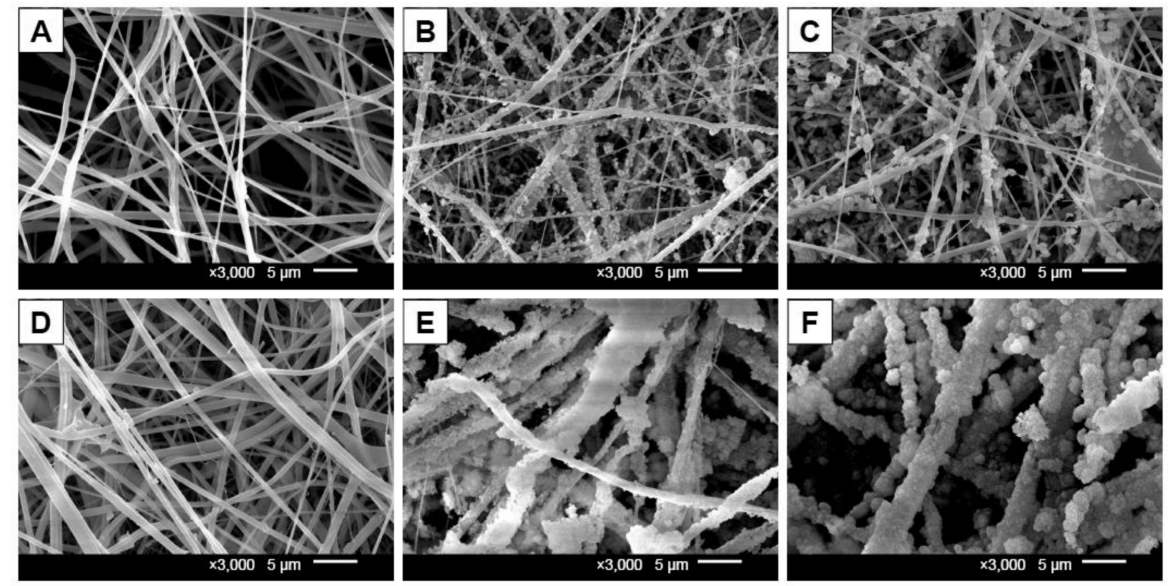

Figure 8. Ag-CaP/CS fibers after immersion in SBF: (A) CS, (B) A0, and (C) A1 for 1 week; (D) CS, (E) A0, and (F) A1 for 2 weeks, where CS-chitosan; A0-CS:CaP:Ag = 4:1:0\%; A1- CS:CaP:Ag = 4:1:0.075\%. (Reprinted with permission from the authors of [104] Copyright 2018, Dove Medical Press Limited).

\subsection{Other Polymer/HA Nanocomposited Electrospun Fibers}

Various other polymers such as polyvinyl alcohol [105], PU [106], gelatin [107,108], polyacrylonitrile (PAN) [109], and collagen $[110,111]$ have also been used to incorporate HA to produce nanofibrous composites for tissue engineering applications. With the abovementioned work, the main concept behind the incorporation of calcium phosphate materials such as HA or $\beta$-TCP to various polymeric material to form a nanocomposite fibrous material is to mimic the natural ECM, thereby increasing its functionality during implant in host tissue. The structure and characteristics of scaffold materials play an important role in determining the success of the implant. As discussed previously, electrospinning is a versatile technique that provides a structure related to the ECM. Various biopolymers possess good biocompatibility, biodegradability, and are nontoxic in nature. However, the incorporation of certain mineral components can enhance specific functional characteristics such as mineralization and osseointegration. The addition of $\mathrm{CaP}$ materials to polymers enhances cell infiltration, differentiation, and biomineralization. Furthermore, a combination of polymers and HA has also been attempted by several researchers $[60,75,77,91,110]$. Kwon et al. prepared collagen HA nanocomposite fibers laminated over polydopamine (PDA)coated microfibrous PLGA fabrics. Their studies revealed that collagen/HA nanocomposite fibers can be used as 3D scaffolds with architectural support of PLGA [110]. Samadian et al. reported that HA-decorated carbon nanofibers (CNFs) were obtained by electrospinning [109]. CNFs were derived from heat treatment of electrospun PAN fibers, and these CNFs were mineralized using a biomimetic process. Prior to the mineralization process, 
the surface of $\mathrm{CNF}$ s was activated by $\mathrm{NaOH}$ solution to form a carbonyl functional group. These groups act as nucleation sites for mineralization (Figure 9).

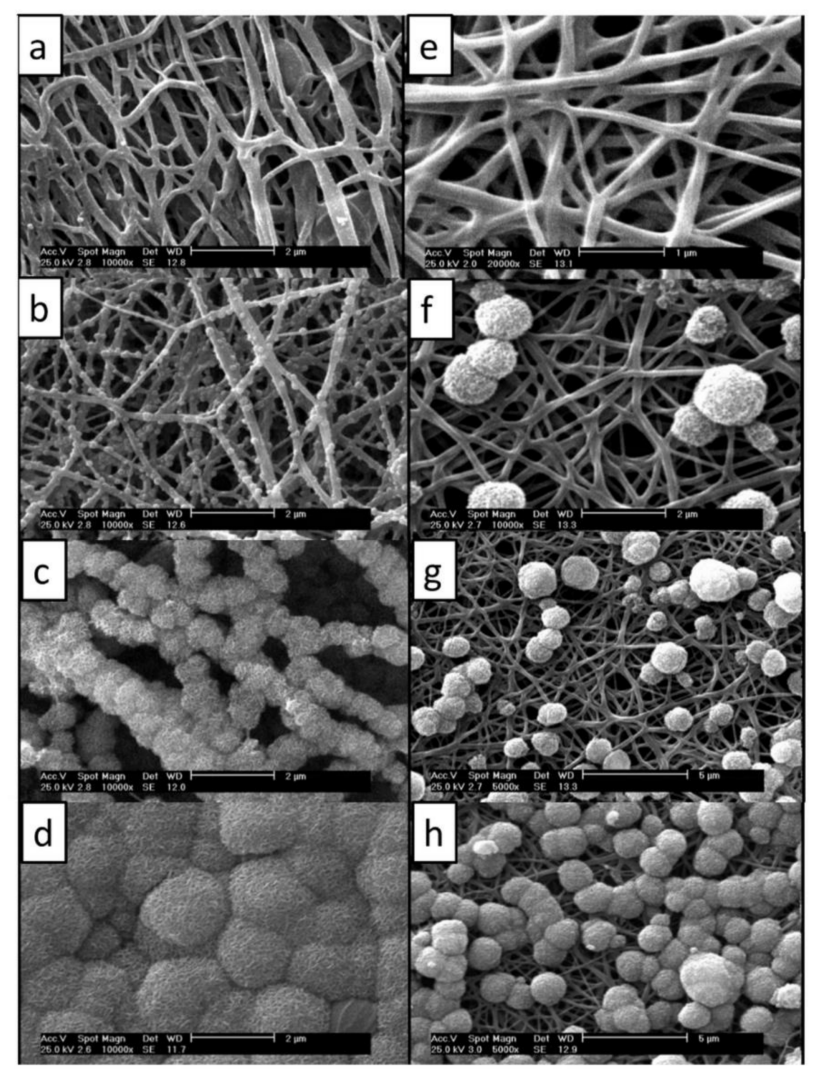

Figure 9. Scanning electron microscopy (SEM) images of (a-d) pristine carbon nanofibers (CNFs) and (e-h) NaOH-treated CNFs incubated in simulated body fluid (SBF) for (a,e) 12 h, (b,f) 24 h, (c,g) 48 h, and (d,h) 72 h. (Reprinted under Creative Common CC BY license from [109] Copyright (2020), Springer Nature).

To overcome bone infection following implantation, PLLA/HA electrospun nanocomposite fibers were coated with PDA by self-polymerization of dopamine (DA) to produce PLLA/HA/PDA composite fibers [112]. To incorporate Ag, a polypyrrole (Py)-mediated electrochemical approach was implemented for the formation of the PLLA/HA/PDA/PPy/ $\mathrm{Ag}$ nanocomposited fiber (Figure 10). At an optimized time of $24 \mathrm{~h}$ and $0.5 \mathrm{~g} . \mathrm{L}^{-1}$, nanoparticles were evenly distributed on the nanofiber surface. Owing to the combination of PDA and PPy, the release rate of $\mathrm{Ag}^{+}$was controlled and stable, which promoted a long antibacterial effect. Nucleation and growth of apatite mineralization was enhanced by the hydrophilic $-\mathrm{OH}$ and $-\mathrm{NH}_{2}$ groups present in PDA. Moreover, in vitro analysis revealed excellent cell viability for osteoblast cells. Therefore, this composite fiber can act as a bone repair material and a one to inhibit bone infection.

Another recent study reported that electrospun calcium chloride complexed polyamide66 (PA66) that can resemble the ECM [113]. The addition of $\mathrm{CaCl}_{2}$ increased the mechanical characteristics such as tensile strength and modulus, and $\mathrm{Ca}^{2+}$ ions acted as nucleation sites for mineralized apatite formation on the surface of nanofibers, resulting in an aHA/PA66/ CaCl2 composite scaffold, and the mechanical strength was further enhanced. In vitro analysis revealed that the cell viability increased with the electrospun calcium chloride complexed PA66 compared to that with pristine PA66 fibers. Over a prolonged period, the $\mathrm{HA} / \mathrm{PA} 66 / \mathrm{CaCl} 2$ composite scaffold showed promising signs to promote cell proliferation and growth. Collectively, these results revealed that this composite resembles bone structure, chemistry, and biology and can be a good candidate for bone tissue engineering. Raic et al. recently reported about cationic electrospun bovine serum albumin 
(BSA) fibers with surface charge to guide osteogenic cell differentiation [114]. This work was interesting as the authors used pure protein as a polymer material and determined its effect on topography and cell differentiation. BSA was modified with amino groups to resemble the ECM both in chemistry and architecture. HA was mineralized by immersion in SBF. The results revealed that the fibrous structure and surface charge considerably affected osteogenic differentiation and mineralization.

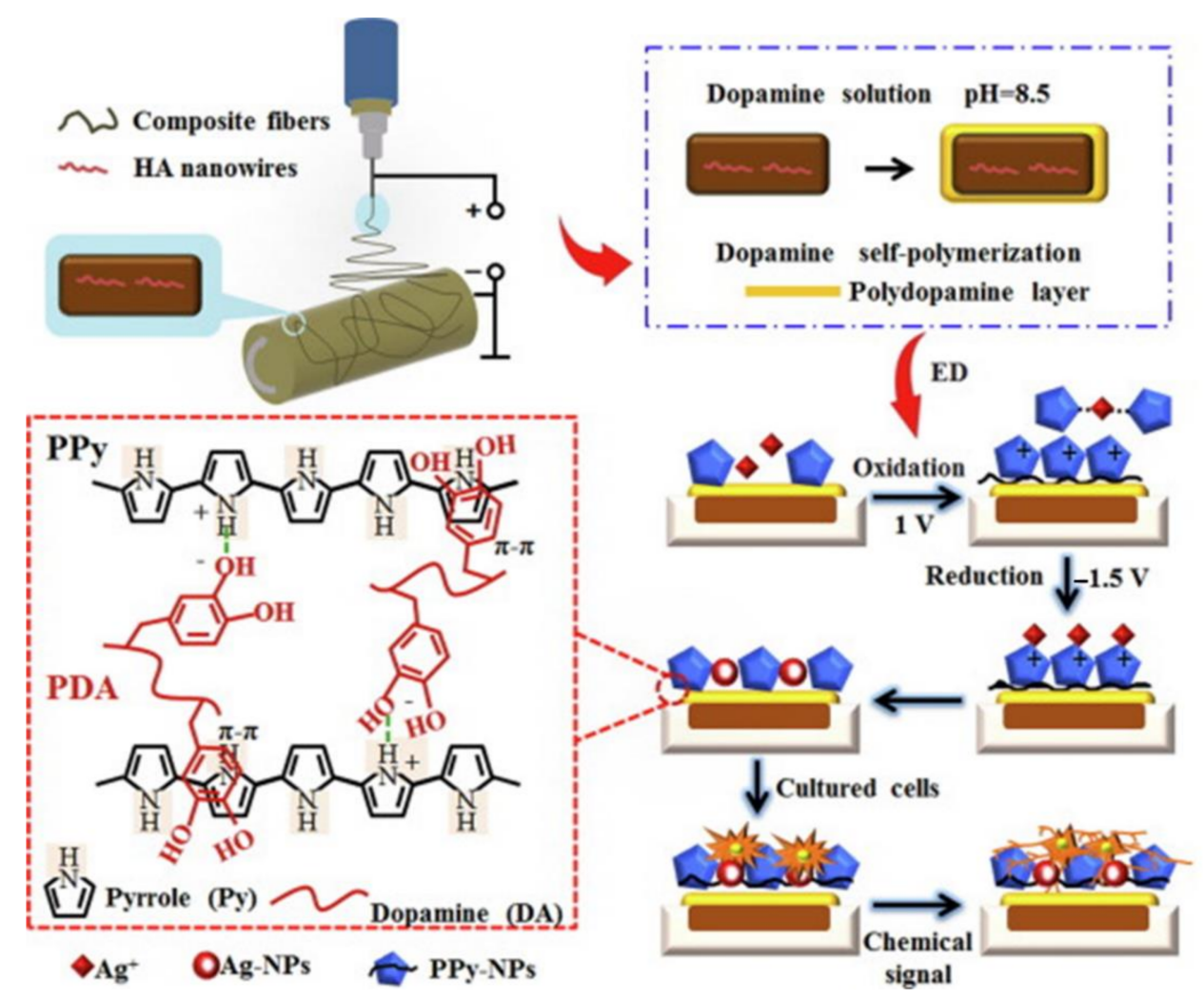

Figure 10. Synthesis of the PLLA/HA/PDA/PPy/Ag nanofibrous composite for bone repair and inhibition of bone infection. (Reprinted with permission from the authors of [112] Copyright (2020), Elsevier).

\section{Conclusions and Future Perspectives}

Bone tissue engineering is difficult, with several complexities from the design perspective. Recently, polymer-based hybrid/composite materials have attracted considerable attention owing to their tunable mechanical properties, biocompatibility, flexibility, low toxicity, and biodegradability. The development of pioneering methods as well as new materials and combinations may benefit the customization of biomaterials for particular tissue engineering applications. Electrospinning is a simple and flexible procedure that produces nanofibers that can be used for various biomedical applications. The advantage of electrospinning is that, with optimized parameters, electrospun nanofibers can be controlled and reproduced for various applications. CaP-based materials have great potential for use in bone tissue engineering applications. The electrospinning combination of biopolymers with CaP-based materials is an advantage for spatial control over morphology and structural design, while imparting necessary cell behavior. However, it is crucial to select the appropriate polymer material based on the area of electrospun material to be used in clinical applications, such as wound healing, bone repair, and infection control. Therefore, it is essential to recognize the underlying mechanism and to use theoretical approaches for the development of such hybrid materials. It is clear from the results discussed above that these reports were from laboratory studies, and the development of these hybrid composite nanofibers for real-time applications on a large scale is yet to be determined, as it will create numerous concerns. Unlike other industrial applications, tissue engineering 
materials used in biological environments require verification of the finest performance prior to use for practical applications and subsequent clinical approval. This will pose challenges in the field, and qualitative research and improvement are warranted. However, latest developments in this field will provide a way for the improvement of stealth hybrid nanocomposite fibers with multifunctional features that can address common challenges experienced in tissue engineering.

Funding: This research was supported by Yeungnam University research grants in 2020.

Institutional Review Board Statement: Not applicable.

Informed Consent Statement: Not applicable.

Data Availability Statement: Data sharing not applicable.

Conflicts of Interest: The authors declare no conflict of interest.

\section{References}

1. Su, Y.; Cockerill, I.; Zheng, Y.; Tang, L.; Qin, Y.-X.; Zhu, D. Biofunctionalization of metallic implants by calcium phosphate coatings. Bioact. Mater. 2019, 4, 196-206. [CrossRef]

2. Nathanael, A.J.; Oyane, A.; Nakamura, M.; Sakamaki, I.; Nishida, E.; Kanemoto, Y.; Miyaji, H. In Vitro and in Vivo Analysis of Mineralized Collagen-Based Sponges Prepared by a Plasma- and Precursor-Assisted Biomimetic Process. ACS Appl. Mater. Interfaces 2017, 9, 22185-22194. [CrossRef]

3. Nathanael, A.J.; Oyane, A.; Nakamura, M.; Mahanti, M.; Koga, K.; Shitomi, K.; Miyaji, H. Rapid and area-specific coating of fluoride-incorporated apatite layers by a laser-assisted biomimetic process for tooth surface functionalization. Acta Biomater. 2018, 79, 148-157. [CrossRef] [PubMed]

4. Huang, L.; Zhou, B.; Wu, H.; Zheng, L.; Zhao, J. Effect of apatite formation of biphasic calcium phosphate ceramic (BCP) on osteoblastogenesis using simulated body fluid (SBF) with or without bovine serum albumin (BSA). Mater. Sci. Eng. C 2017, 70, 955-961. [CrossRef] [PubMed]

5. Duan, R.; Barbieri, D.; Luo, X.; Weng, J.; De Bruijn, J.D.; Yuan, H. Submicron-surface structured tricalcium phosphate ceramic enhances the bone regeneration in canine spine environment. J. Orthop. Res. 2016, 34, 1865-1873. [CrossRef]

6. Chiba, S.; Anada, T.; Suzuki, K.; Saito, K.; Shiwaku, Y.; Miyatake, N.; Baba, K.; Imaizumi, H.; Hosaka, M.; Itoi, E.; et al. Effect of resorption rate and osteoconductivity of biodegradable calcium phosphate materials on the acquisition of natural bone strength in the repaired bone. J. Biomed. Mater. Res. Part A 2016, 104, 2833-2842. [CrossRef]

7. Abdal-Hay, A.; Abbasi, N.; Gwiazda, M.; Hamlet, S.; Ivanovski, S. Novel polycaprolactone/hydroxyapatite nanocomposite fibrous scaffolds by direct melt-electrospinning writing. Eur. Polym. J. 2018, 105, 257-264. [CrossRef]

8. Rogina, A.; Rico, P.; Ferrer, G.G.; Ivankovic, M.; Ivankovic, H. Effect of in situ formed hydroxyapatite on microstructure of freeze-gelled chitosan-based biocomposite scaffolds. Eur. Polym. J. 2015, 68, 278-287. [CrossRef]

9. Jang, H.L.; Jin, K.; Lee, J.; Kim, Y.; Nahm, S.H.; Hong, K.S.; Nam, K.T. Revisiting Whitlockite, the Second Most Abundant Biomineral in Bone: Nanocrystal Synthesis in Physiologically Relevant Conditions and Biocompatibility Evaluation. ACS Nano 2014, 8, 634-641. [CrossRef]

10. Groza, A.; Dreghici, D.B.; Ganciu, M. Calcium Phosphate Layers Deposited on Thermal Sensitive Polymer Substrates in Radio Frequency Magnetron Plasma Discharge. Coatings 2019, 9, 709. [CrossRef]

11. Jeong, J.; Kim, J.H.; Shim, J.H.; Hwang, N.S.; Heo, C.Y. Bioactive calcium phosphate materials and applications in bone regeneration. Biomater. Res. 2019, 23, 1-11. [CrossRef]

12. Okada, M.; Matsumoto, T. Synthesis and modification of apatite nanoparticles for use in dental and medical applications. Jpn. Dent. Sci. Rev. 2015, 51, 85-95. [CrossRef]

13. Nathanael, A.J.; Hong, S.I.; Mangalaraj, D.; Ponpandian, N.; Chen, P.C. Template-Free Growth of Novel Hydroxyapatite Nanorings: Formation Mechanism and Their Enhanced Functional Properties. Cryst. Growth Des. 2012, 12, 3565-3574. [CrossRef]

14. Matsunaga, K.; Kubota, T.; Toyoura, K.; Nakamura, A. First-principles calculations of divalent substitution of Ca 2+ in tricalcium phosphates. Acta Biomater. 2015, 23, 329-337. [CrossRef]

15. Galea, L.G.; Bohner, M.; Lemaître, J.; Kohler, T.; Müller, R. Bone substitute: Transforming $\beta$-tricalcium phosphate porous scaffolds into monetite. Biomaterials 2008, 29, 3400-3407. [CrossRef]

16. Maitz, M.F. Applications of synthetic polymers in clinical medicine. Biosurface Biotribol. 2015, 1, 161-176. [CrossRef]

17. Bat, E.; Zhang, Z.; Feijen, J.; Grijpma, D.W.; Poot, A.A. Biodegradable elastomers for biomedical applications and regenerative medicine. Regen. Med. 2014, 9, 385-398. [CrossRef] [PubMed]

18. Goreninskii, S.I.; Bogomolova, N.N.; Malchikhina, A.I.; Golovkin, A.; Bolbasov, E.N.; Safronova, T.; Putlyaev, V.I.; Tverdokhlebov, S. Biological Effect of the Surface Modification of the Fibrous Poly(L-lactic acid) Scaffolds by Radio Frequency Magnetron Sputtering of Different Calcium-Phosphate Targets. BioNanoScience 2017, 7, 50-57. [CrossRef] 
19. Liao, Y.; Loh, C.-H.; Tian, M.; Wang, R.; Fane, A.G. Progress in electrospun polymeric nanofibrous membranes for water treatment: Fabrication, modification and applications. Prog. Polym. Sci. 2018, 77, 69-94. [CrossRef]

20. Boys, C.V. On the Production, Properties, and some suggested Uses of the Finest Threads. Proc. Phys. Soc. Lond. 1887, 9, 8-19. [CrossRef]

21. Xue, J.; Wu, T.; Dai, Y.; Xia, Y. Electrospinning and Electrospun Nanofibers: Methods, Materials, and Applications. Chem. Rev. 2019, 119, 5298-5415. [CrossRef]

22. Zhang, S.; Yang, D.; Jing, D.; Liu, H.; Liu, L.; Jia, Y.; Gao, M.; Guo, L.; Huo, Z. Enhanced photodynamic therapy of mixed phase TiO2(B)/anatase nanofibers for killing of HeLa cells. Nano Res. 2014, 7, 1659-1669. [CrossRef]

23. Zhang, W.; Xu, X.; Chai, Y.; Wang, Y. Synthesis and characterization of Zn 2+ and SeO 32 - co-substituted nano-hydroxyapatite. Adv. Powder Technol. 2016, 27, 1857-1861. [CrossRef]

24. Liu, L.; Huang, J.; Feng, Y.; Liu, J.; Yu, X. Synthesis and characterization of ultralong nanofibrillar and hydroxyapatite powder. Adv. Powder Technol. 2015, 26, 428-433. [CrossRef]

25. Xu, Y.; An, L.; Chen, L.; Xu, H.; Zeng, D.; Wang, G. Controlled hydrothermal synthesis of strontium-substituted hydroxyapatite nanorods and their application as a drug carrier for proteins. Adv. Powder Technol. 2018, 29, 1042-1048. [CrossRef]

26. Strnad, G.; Petrovan, C.; Russu, O.; Jakab-Farkas, L. TiO2nanostructured surfaces for biomedical applications developed by electrochemical anodization. IOP Conf. Ser. Mater. Sci. Eng. 2016, 161, 012051. [CrossRef]

27. Thenmozhi, S.; Dharmaraj, N.; Kadirvelu, K.; Kim, H.Y. Electrospun nanofibers: New generation materials for advanced applications. Mater. Sci. Eng. B 2017, 217, 36-48. [CrossRef]

28. Rajzer, I. Fabrication of bioactive polycaprolactone/hydroxyapatite scaffolds with final bilayer nano-/micro-fibrous structures for tissue engineering application. J. Mater. Sci. 2014, 49, 5799-5807. [CrossRef]

29. Pelipenko, J.; Kristl, J.; Janković, B.; Baumgartner, S.; Kocbek, P. The impact of relative humidity during electrospinning on the morphology and mechanical properties of nanofibers. Int. J. Pharm. 2013, 456, 125-134. [CrossRef]

30. Haider, A.; Haider, S.; Kang, I.-K. A comprehensive review summarizing the effect of electrospinning parameters and potential applications of nanofibers in biomedical and biotechnology. Arab. J. Chem. 2018, 11, 1165-1188. [CrossRef]

31. Rehman, F.U.; Zhao, C.; Jiang, H.; Wang, X. Biomedical applications of nano-titania in theranostics and photodynamic therapy. Biomater. Sci. 2016, 4, 40-54. [CrossRef]

32. Bancelin, S.; Aimé, C.; Gusachenko, I.; Kowalczuk, L.; Latour, G.; Coradin, T.; Schanne-Klein, M.-C. Determination of collagen fibril size via absolute measurements of second-harmonic generation signals. Nat. Commun. 2014, 5, 4920. [CrossRef]

33. Wang, X.; Ding, B.; Li, B. Biomimetic electrospun nanofibrous structures for tissue engineering. Mater. Today 2013, 16, 229-241. [CrossRef] [PubMed]

34. Venugopal, J.R.; Radhakrishnan, S.; Ravichandran, R.; Mukherjee, S.; Balamurugan, R.; Sundarrajan, S.; Ramakrishna, S. Nanofibrous structured biomimetic strategies for skin tissue regeneration. Wound Repair Regen. 2012, 21, 1-16. [CrossRef]

35. Dias, J.; Granja, P.; Bártolo, P. Advances in electrospun skin substitutes. Prog. Mater. Sci. 2016, 84, 314-334. [CrossRef]

36. Bonadies, I.; Maglione, L.; Ambrogi, V.; Paccez, J.D.; Zerbini, L.F.; E Silva, L.F.R.; Picanço, N.S.; Tadei, W.P.; Grafova, I.; Grafov, A.; et al. Electrospun core/shell nanofibers as designed devices for efficient Artemisinin delivery. Eur. Polym. J. 2017, 89, 211-220. [CrossRef]

37. Pant, B.; Park, M.; Park, S.J. Drug Delivery Applications of Core-Sheath Nanofibers Prepared by Coaxial Electrospinning: A Review. Pharmaceutics 2019, 11, 305. [CrossRef] [PubMed]

38. Sahay, R.; Kumar, P.S.; Sridhar, R.; Sundaramurthy, J.; Venugopal, J.R.; Mhaisalkar, S.G.; Ramakrishna, S. Electrospun composite nanofibers and their multifaceted applications. J. Mater. Chem. 2012, 22, 12953-12971. [CrossRef]

39. Chinnappan, A.; Baskar, C.; Baskar, S.; Ratheesh, G.; Ramakrishna, S. An overview of electrospun nanofibers and their application in energy storage, sensors and wearable/flexible electronics. J. Mater. Chem. C 2017, 5, 12657-12673. [CrossRef]

40. Han, W.; Wang, Y.; Su, J.; Xin, X.; Guo, Y.; Long, Y.-Z.; Ramakrishna, S. Fabrication of nanofibrous sensors by electrospinning. Sci. China Ser. E: Technol. Sci. 2019, 62, 886-894. [CrossRef]

41. Aliheidari, N.; Aliahmad, N.; Agarwal, M.; Dalir, H. Electrospun Nanofibers for Label-Free Sensor Applications. Sensors 2019, 19, 3587. [CrossRef]

42. Li, Y.; Mohammed, A.; Tang, L.; Li, D.; Wang, L. Electrospun Nanofibers for Sensors. In Electrospinning: Nanofabrication and Applications; William Andrew Publishing: Norwich, NY, USA, 2019; pp. 571-601.

43. Sun, G.; Sun, L.; Xie, H.; Liu, J. Electrospinning of Nanofibers for Energy Applications. Nanomaterials 2016, 6, 129. [CrossRef] [PubMed]

44. Ma, Y.; Ma, Y.; Liu, M.; Chen, Y.; Hu, X.; Ye, Z.; Dong, D. Study on Nanofibrous Catalysts Prepared by Electrospinning for Methane Partial Oxidation. Catalysts 2019, 9, 479. [CrossRef]

45. Gopiraman, M.; Bang, H.; Yuan, G.; Yin, C.; Song, K.-H.; Lee, J.; Chung, I.-M.; Karvembu, R.; Kim, I.S. Noble metal/functionalized cellulose nanofiber composites for catalytic applications. Carbohydr. Polym. 2015, 132, 554-564. [CrossRef] [PubMed]

46. Horiuchi, N.; Maeda, T. Statins and bone metabolism. Oral Dis. 2006, 12, 85-101. [CrossRef]

47. Papapoulos, S.E. Bisphosphonates: How do they work? Best Pr. Res. Clin. Endocrinol. Metab. 2008, 22, 831-847. [CrossRef] [PubMed]

48. Song, J.; Zhu, G.; Wang, L.; An, G.; Shi, X.; Wang, Y. Assembling of electrospun meshes into three-dimensional porous scaffolds for bone repair. Biofabrication 2017, 9, 015018. [CrossRef] [PubMed] 
49. Stastna, E.; Ćástková, K.; Ráhel', J. Influence of Hydroxyapatite Nanoparticles and Surface Plasma Treatment on Bioactivity of Polycaprolactone Nanofibers. Polymers 2020, 12, 1877. [CrossRef]

50. Hassan, M.I.; Sun, T.; Sultana, N. Fabrication of Nanohydroxyapatite/Poly(caprolactone) Composite Microfibers Using Electrospinning Technique for Tissue Engineering Applications. J. Nanomater. 2014, 2014, 1-7. [CrossRef]

51. Jabur, A.R.; Al-Hassani, E.S.; Al-Shammari, A.M.; Najim, M.A.; Hassan, A.A.; Ahmed, A.A. Evaluation of Stem Cells' Growth on Electrospun Polycaprolactone (PCL) Scaffolds Used for Soft Tissue Applications. Energy Procedia 2017, 119, 61-71. [CrossRef]

52. Dong, L.; Wang, S.-J.; Zhao, X.-R.; Zhu, Y.; Yu, J.-K. 3D-Printed Poly( $\varepsilon$-caprolactone) Scaffold Integrated with Cell-laden Chitosan Hydrogels for Bone Tissue Engineering. Sci. Rep. 2017, 7, 1-9. [CrossRef]

53. Dai, N.-T.; Williamson, M.; Khammo, N.; Adams, E.; Coombes, A. Composite cell support membranes based on collagen and polycaprolactone for tissue engineering of skin. Biomaterials 2004, 25, 4263-4271. [CrossRef] [PubMed]

54. Hu, Y.; Feng, B.; Zhang, W.; Yan, C.; Yao, Q.; Shao, C.; Yu, F.; Li, F.; Fu, Y. Electrospun gelatin/PCL and collagen/PCL scaffolds for modulating responses of bone marrow endothelial progenitor cells. Exp. Ther. Med. 2019, 17, 3717-3726. [CrossRef]

55. Gniesmer, S.; Brehm, R.; Hoffmann, A.; De Cassan, D.; Menzel, H.; Hoheisel, A.; Glasmacher, B.; Willbold, E.; Reifenrath, J.; Wellmann, M.; et al. In vivo analysis of vascularization and biocompatibility of electrospun polycaprolactone fibre mats in the rat femur chamber. J. Tissue Eng. Regen. Med. 2019, 13, 1190-1202. [CrossRef]

56. Gredes, T.; Schönitz, S.; Gedrange, T.; Stepien, L.; Kozak, K.; Kunert-Keil, C. In vivo analysis of covering materials composed of biodegradable polymers enriched with flax fibers. Biomater. Res. 2017, 21, 1-12. [CrossRef] [PubMed]

57. Li, H.; Huang, C.; Jin, X.; Ke, Q. An electrospun poly( $\varepsilon$-caprolactone) nanocomposite fibrous mat with a high content of hydroxyapatite to promote cell infiltration. RSC Adv. 2018, 8, 25228-25235. [CrossRef]

58. Deliormanl, A.M.; Konyalı, R. Preparation and characterization of electrospun poly ( $\varepsilon$-caprolactone)-bioactive glass/HA biocomposite nanofibers. J. Aust. Ceram. Soc. 2019, 55, 247-256. [CrossRef]

59. Nazarnezhad, S.; Baino, F.; Shin, H.W.; Webster, T.J.; Kargozar, S. Electrospun Nanofibers for Improved Angiogenesis: Promises for Tissue Engineering Applications. Nanomaterials 2020, 10, 1609. [CrossRef] [PubMed]

60. Ye, H.; Zhu, J.; Deng, D.; Jin, S.; Li, J.; Man, Y. Enhanced osteogenesis and anewgiogenesis by PCL/chitosan/Sr-doped calcium phosphate electrospun nanocomposite membrane for guided bone regeneration. J. Biomater. Sci. Polym. Ed. 2019, 30, 1505-1522. [CrossRef] [PubMed]

61. Bose, S.; Fielding, G.; Tarafder, S.; Bandyopadhyay, A. Understanding of dopant-induced osteogenesis and angiogenesis in calcium phosphate ceramics. Trends Biotechnol. 2013, 31, 594-605. [CrossRef] [PubMed]

62. Hassan, M.I.; Sultana, N.; Hamdan, S. Bioactivity Assessment of Poly( $\epsilon$-caprolactone)/Hydroxyapatite Electrospun Fibers for Bone Tissue Engineering Application. J. Nanomater. 2014, 2014, 1-6. [CrossRef]

63. Keivani, F.; Shokrollahi, P.; Zandi, M.; Irani, S.; Shokrollahi, P.; Khorasani, S. Engineered electrospun poly(caprolactone)/ polycaprolactone-g-hydroxyapatite nano-fibrous scaffold promotes human fibroblasts adhesion and proliferation. Mater. Sci. Eng. C 2016, 68, 78-88. [CrossRef]

64. Hanas, T.; Kumar, T.S.; Perumal, G.; Doble, M.; Ramakrishna, S. Electrospun PCL/HA coated friction stir processed AZ31/HA composites for degradable implant applications. J. Mater. Process. Technol. 2018, 252, 398-406. [CrossRef]

65. Shitole, A.A.; Raut, P.W.; Sharma, N.; Giram, P.; Khandwekar, A.P.; Garnaik, B. Electrospun polycaprolactone/hydroxyapatite/ZnO nanofibers as potential biomaterials for bone tissue regeneration. J. Mater. Sci. Mater. Med. 2019, 30, 51. [CrossRef]

66. Johari, N.; Fathi, M.; Fereshteh, Z.; Kargozar, S.; Samadikuchaksaraei, A. The electrospun poly( $(\varepsilon$-caprolactone)/fluoridated hydroxyapatite nanocomposite for bone tissue engineering. Polym. Adv. Technol. 2019, 31, 1019-1026. [CrossRef]

67. Rivero, G.; Aldana, A.A.; Lopez, Y.R.F.; Liverani, L.; Boccacini, A.R.; Bustos, D.M.; Abraham, G.A. 14-3-3 $\varepsilon$ protein-immobilized PCL-HA electrospun scaffolds with enhanced osteogenicity. J. Mater. Sci. Mater. Med. 2019, 30, 99. [CrossRef]

68. Elmowafy, E.M.; Tiboni, M.; Soliman, M.E. Biocompatibility, biodegradation and biomedical applications of poly(lactic acid)/ poly(lactic-co-glycolic acid) micro and nanoparticles. J. Pharm. Investig. 2019, 49, 347-380. [CrossRef]

69. Martins, C.; Sousa, F.; Araújo, F.; Sarmento, B. Functionalizing PLGA and PLGA Derivatives for Drug Delivery and Tissue Regeneration Applications. Adv. Health Mater. 2018, 7, 1-24. [CrossRef] [PubMed]

70. Yang, X.; Li, Y.; He, W.; Huang, Q.; Zhang, R.; Feng, Q. Hydroxyapatite/collagen coating on PLGA electrospun fibers for osteogenic differentiation of bone marrow mesenchymal stem cells. J. Biomed. Mater. Res. Part A 2018, 106, 2863-2870. [CrossRef] [PubMed]

71. Zhou, H.; Lawrence, J.G.; Bhaduri, S.B. Fabrication aspects of PLA-CaP/PLGA-CaP composites for orthopedic applications: A review. Acta Biomater. 2012, 8, 1999-2016. [CrossRef]

72. Jose, M.V.; Thomas, V.; Johnson, K.T.; Dean, D.; Nyairo, E. Aligned PLGA/HA nanofibrous nanocomposite scaffolds for bone tissue engineering. Acta Biomater. 2009, 5, 305-315. [CrossRef] [PubMed]

73. Zhang, H.; Chen, Z. Fabrication and Characterization of Electrospun PLGA/MWNTs/ Hydroxyapatite Biocomposite Scaffolds for Bone Tissue Engineering. J. Bioact. Compat. Polym. 2010, 25, 241-259. [CrossRef]

74. Fu, C.; Bai, H.; Zhu, J.; Niu, Z.; Wang, Y.; Li, J.; Yang, X.-Y.; Bai, Y. Enhanced cell proliferation and osteogenic differentiation in electrospun PLGA/hydroxyapatite nanofibre scaffolds incorporated with graphene oxide. PLoS ONE 2017, 12, e0188352. [CrossRef] [PubMed] 
75. Mustafa, W.; Azhar, U.; Tabassum, S.; Jamal, M.; Siddiqi, S.A.; Tariq, M.; Muhammad, N.; Asif, A.; Chaudhry, A.A.; Sharif, F. Doping and Incorporation of Hydroxyapatite in Development of PU-PLA Electrospun Osteogenic Membranes. J. Polym. Environ. 2020, 28, 2988-3002. [CrossRef]

76. Radwan-Pragłowska, J.; Janus, Ł.; Piątkowski, M.; Bogdał, D.; Matýsek, D. 3D Hierarchical, Nanostructured Chitosan/PLA/HA Scaffolds Doped with TiO2/Au/Pt NPs with Tunable Properties for Guided Bone Tissue Engineering. Polymers 2020, 12, 792. [CrossRef]

77. Magiera, A.; Markowski, J.; Menaszek, E.; Pilch, J.; Blazewicz, S. PLA-Based Hybrid and Composite Electrospun Fibrous Scaffolds as Potential Materials for Tissue Engineering. J. Nanomater. 2017, 2017, 1-11. [CrossRef]

78. Kareem, M.M.; Tanner, K.E. Optimising micro-hydroxyapatite reinforced poly(lactide acid) electrospun scaffolds for bone tissue engineering. J. Mater. Sci. Mater. Med. 2020, 31, 1-13. [CrossRef]

79. Kwak, S.; Haider, A.; Gupta, K.C.; Kim, S.; Kang, I.-K. Micro/Nano Multilayered Scaffolds of PLGA and Collagen by Alternately Electrospinning for Bone Tissue Engineering. Nanoscale Res. Lett. 2016, 11, 1-16. [CrossRef] [PubMed]

80. Fu, Q.-W.; Zi, Y.-P.; Xu, W.; Zhou, R.; Cai, Z.-Y.; Zheng, W.-J.; Chen, F.; Qian, Q.-R. Electrospinning of calcium phosphate-poly (d,l-lactic acid) nanofibers for sustained release of water-soluble drug and fast mineralization. Int. J. Nanomed. 2016, 11, 5087-5097. [CrossRef] [PubMed]

81. Puppi, D.; Pecorini, G.; Chiellini, F. Biomedical Processing of Polyhydroxyalkanoates. Bioengineering 2019, 6, 108. [CrossRef]

82. Ray, S.; Kalia, V.C. Biomedical Applications of Polyhydroxyalkanoates. Indian J. Microbiol. 2017, 57, 261-269. [CrossRef]

83. Williams, S.F.; Martin, D.P. Applications of Polyhydroxyalkanoates (PHA) in Medicine and Pharmacy. Biopolym. Online 2002. [CrossRef]

84. Hazer, D.B.; Kılıçay, E.; Hazer, B. Poly(3-hydroxyalkanoate)s: Diversification and biomedical applications. Mater. Sci. Eng. C 2012, 32, 637-647. [CrossRef]

85. Sadat-Shojai, M. Electrospun Polyhydroxybutyrate/Hydroxyapatite Nanohybrids: Microstructure and Bone Cell Response. J. Mater. Sci. Technol. 2016, 32, 1013-1020. [CrossRef]

86. Li, M.; Mondrinos, M.J.; Chen, X.; Gandhi, M.R.; Ko, F.K.; Lelkes, P.I. Co-electrospun poly(lactide-co-glycolide), gelatin, and elastin blends for tissue engineering scaffolds. J. Biomed. Mater. Res. Part A 2006, 79, 963-973. [CrossRef] [PubMed]

87. Ni, J.; Wang, M. In vitro evaluation of hydroxyapatite reinforced polyhydroxybutyrate composite. Mater. Sci. Eng. C 2002, 20, 101-109. [CrossRef]

88. Doyle, C.; Tanner, E.; Bonfield, W. In vitro and in vivo evaluation of polyhydroxybutyrate and of polyhydroxybutyrate reinforced with hydroxyapatite. Biomaterials 1991, 12, 841-847. [CrossRef]

89. Sanhueza, C.; Acevedo, F.; Rocha, S.; Villegas, P.; Seeger, M.; Navia, R. Polyhydroxyalkanoates as biomaterial for electrospun scaffolds. Int. J. Biol. Macromol. 2019, 124, 102-110. [CrossRef] [PubMed]

90. Alves, A.K.; Viezzer, M.M.D.C.F.C.; Berutti, A.K.A.F.A.; Bergmann, C.P. Effect of Electrospun Phb and Hap-Phb Composite Scaffolds Characteristics on Mesenchymal Stem Cell Growth Viability. MOJ Appl. Bionics Biomech. 2017, 1, 1-8. [CrossRef]

91. Keikhaei, S.; Mohammadalizadeh, Z.; Karbasi, S.; Salimi, A. Evaluation of the effects of $\beta$-tricalcium phosphate on physical, mechanical and biological properties of Poly (3-hydroxybutyrate)/chitosan electrospun scaffold for cartilage tissue engineering applications. Mater. Technol. 2019, 34, 615-625. [CrossRef]

92. Tanadchangsaeng, N.; Boonyagul, S. Physical properties and morphology of electrospun composite fiber mats of polyhydroxyalkanoate containing nanoclay and tricalcium phosphate additives. IOP Conf. Ser. Mater. Sci. Eng. 2018, $369,012013$. [CrossRef]

93. Zhao, D.; Wang, Y.; Xu, R.; Wu, G.; Zhao, X.; Yu, D.; Cui, F.; Chen, D.; Tian, W. Composition-graded Films of Fluoroapatite/PHB Fabricated via Electrospinning for Tissue Engineering. J. Bioact. Compat. Polym. 2007, 22, 379-393. [CrossRef]

94. Vunain, E.; Mishra, A.; Mamba, B. Fundamentals of chitosan for biomedical applications. Chitosan Based Biomater. 2017, 1, 3-30. [CrossRef]

95. Hu, L.; Meng, X.; Xing, R.; Liu, S.; Chen, R.; Qin, Y.; Yu, H.; Li, P. Design, synthesis and antimicrobial activity of 6-N-substituted chitosan derivatives. Bioorganic Med. Chem. Lett. 2016, 26, 4548-4551. [CrossRef]

96. Zhao, D.; Yu, S.; Sun, B.; Gao, S.; Guo, S.; Zhao, K. Biomedical Applications of Chitosan and Its Derivative Nanoparticles. Polymers 2018, 10, 462. [CrossRef]

97. Tuzlakoglu, K.; Alves, C.M.; Mano, J.F.; Reis, R.L. Production and Characterization of Chitosan Fibers and 3-D Fiber Mesh Scaffolds for Tissue Engineering Applications. Macromol. Biosci. 2004, 4, 811-819. [CrossRef]

98. Alves, N.M.; Mano, J.F. Chitosan derivatives obtained by chemical modifications for biomedical and environmental applications. Int. J. Biol. Macromol. 2008, 43, 401-414. [CrossRef] [PubMed]

99. Seol, Y.-J.; Lee, J.-Y.; Park, Y.-J.; Lee, Y.-M.; -Ku, Y.; Rhyu, I.-C.; Lee, S.-J.; Han, S.-B.; Chung, C.-P. Chitosan sponges as tissue engineering scaffolds for bone formation. Biotechnol. Lett. 2004, 26, 1037-1041. [CrossRef] [PubMed]

100. Qasim, S.S.B.; Zafar, M.S.; Najeeb, S.; Khurshid, Z.; Shah, A.H.; Husain, S.; Rehman, I.U. Electrospinning of Chitosan-Based Solutions for Tissue Engineering and Regenerative Medicine. Int. J. Mol. Sci. 2018, 19, 407. [CrossRef]

101. Topsakal, A.; Uzun, M.; Ugar, G.; Ozcan, A.; Altun, E.; Oktar, F.N.; Ikram, F.; Ozkan, O.; Sasmazel, H.T.; Gunduz, O. Development of Amoxicillin-Loaded Electrospun Polyurethane/Chitosan / $\beta \beta$-Tricalcium Phosphate Scaffold for Bone Tissue Regeneration. IEEE Trans. NanoBiosci. 2018, 17, 321-328. [CrossRef] 
102. Liverani, L.; Abbruzzese, F.; Mozetic, P.; Basoli, F.; Rainer, A.; Trombetta, M. Electrospinning of hydroxyapatite-chitosan nanofibers for tissue engineering applications. Asia-Pacific J. Chem. Eng. 2014, 9, 407-414. [CrossRef]

103. Zhang, Y.; Venugopal, J.R.; El-Turki, A.; Ramakrishna, S.; Su, B.; Lim, C.T. Electrospun biomimetic nanocomposite nanofibers of hydroxyapatite/chitosan for bone tissue engineering. Biomaterials 2008, 29, 4314-4322. [CrossRef]

104. Jin, S.; Li, J.; Wang, J.; Jiang, J.; Zuo, Y.; Li, Y.; Yang, F. Electrospun silver ion-loaded calcium phosphate/chitosan antibacterial composite fibrous membranes for guided bone regeneration. Int. J. Nanomed. 2018, 13, 4591-4605. [CrossRef] [PubMed]

105. Hezma, A.M.; El-Rafei, A.M.; El-Bahy, G.S.; Abdelrazzak, A.B. Electrospun Hydroxyapatite Containing Polyvinyl Alcohol Nanofibers Doped with Nanogold for Bone Tissue Engineering. Interceram-Int. Ceram. Rev. 2017, 66, 96-100. [CrossRef]

106. Nahavandizadeh, N.; Rezaei, M. Preparation of Shape Memory Polyurethane/Hydroxyapatite Nanocomposite Scaffolds by Electrospinning Method and Investigation of Their Microstructure and Physical-Mechanical Properties. Polym. Technol. Mater. 2020, 59, 1562-1573. [CrossRef]

107. Panzavolta, S.; Gualandi, C.; Fiorani, A.; Bracci, B.; Focarete, M.L.; Bigi, A. Fast Coprecipitation of Calcium Phosphate Nanoparticles inside Gelatin Nanofibers by Tricoaxial Electrospinning. J. Nanomater. 2016, 2016, 1-7. [CrossRef]

108. Lee, J.-H.; Kim, Y.-J. Hydroxyapatite nanofibers fabricated through electrospinning and sol-gel process. Ceram. Int. 2014, 40, 3361-3369. [CrossRef]

109. Samadian, H.; Mobasheri, H.; Azami, M.; Majidi, R.F. Osteoconductive and electroactive carbon nanofibers/hydroxyapatite nanocomposite tailored for bone tissue engineering: In vitro and in vivo studies. Sci. Rep. 2020, 10, 1-14. [CrossRef]

110. Kwon, G.-W.; Gupta, K.C.; Jung, K.-H.; Kang, I.-K. Lamination of microfibrous PLGA fabric by electrospinning a layer of collagen-hydroxyapatite composite nanofibers for bone tissue engineering. Biomater. Res. 2017, 21, 11. [CrossRef]

111. Li, Z.; Zhou, Y.; Yao, H.; Wang, J.; Wang, D.; Liu, Q. Greener synthesis of electrospun collagen/hydroxyapatite composite fibers with an excellent microstructure for bone tissue engineering. Int. J. Nanomed. 2015, 10, 3203-3215. [CrossRef]

112. Liu, F.; Wang, X.; Chen, T.; Zhang, N.; Wei, Q.; Tian, J.; Wang, Y.; Ma, C.; Lu, Y. Hydroxyapatite/silver electrospun fibers for anti-infection and osteoinduction. J. Adv. Res. 2020, 21, 91-102. [CrossRef] [PubMed]

113. Niu, M.X.; Zhao, M.L.; Yin, M.; Huang, D.; Wang, N.; Wei, Y.; Hu, Y.; Lian, X.; Chen, W. Mineralized Polyamide66/Calcium Chloride Nanofibers for Bone Tissue Engineering. Tissue Eng. Part C Methods 2020, 26, 352-363. [CrossRef] [PubMed]

114. Raic, A.; Friedrich, F.; Kratzer, D.; Bieback, K.; Lahann, J.; Lee-Thedieck, C. Potential of electrospun cationic BSA fibers to guide osteogenic MSC differentiation via surface charge and fibrous topography. Sci. Rep. 2019, 9, 20003-20015. [CrossRef] [PubMed] 